\title{
Protein Phosphatase 2A (PP2A) mutations in brain function, development, and neurologic disease
}

Iris VERBINNEN, ${ }^{1,2}$ Pieter VANEYNDE, ${ }^{1,2}$ Sara REYNHOUT, ${ }^{1,2}$ Lisa LENAERTS, $^{1}$ Rita DERUA, ${ }^{1}$ Gunnar HOUGE, ${ }^{3}$ Veerle JANSSENS, ${ }^{1,2}$

${ }^{1}$ Laboratory of Protein Phosphorylation \& Proteomics, Department of Cellular \& Molecular Medicine, University of Leuven (KU Leuven) - Gasthuisberg O\&N1, Herestraat 49, PO-box 901, B-3000 Leuven, Belgium

${ }^{2}$ KU Leuven Brain Institute (LBI), B-3000 Leuven, Belgium

${ }^{3}$ Department of Medical Genetics, Haukeland University Hospital, Bergen, Norway

Commissioned mini-review

Correspondence: Prof. Veerle Janssens (veerle.janssens@kuleuven.be) 


\section{Abstract}

By removing Ser/Thr-specific phosphorylations in a multitude of protein substrates in diverse tissues, Protein Phosphatase type 2A (PP2A) enzymes play essential regulatory roles in cellular signalling and physiology, including in brain function and development. Here, we review current knowledge on PP2A gene mutations causally involved in neurodevelopmental disorders and intellectual disability, focusing on PPP2CA, PPP2R1A and PPP2R5D. We provide insights into the impact of these mutations on PP2A structure, substrate specificity and potential function in neurobiology and brain development.

\section{Introduction}

Protein Phosphatases of type 2A (PP2A) are a family of ubiquitously expressed phosphatases, responsible for the majority of Ser/Thr dephosphorylation in most cell types [1]. By counteracting Ser/Thr-specific protein kinase activity and dephosphorylating several protein substrates in diverse tissues, these phosphatases play essential regulatory roles in cellular signalling and physiology [2], including in brain function and development. The roles of PP2A in neurobiology are highly diverse, yet incompletely understood. While it has been known for a long time that PP2A dysregulation results in neurodegenerative disorders such as Alzheimer's and Parkinson's disease in the aging brain [3-5], recent reports have begun to highlight the role of PP2A dysfunctions in the aetiology of several rare neurodevelopmental disorders (NDD). In this review, we will summarise current knowledge on specific PP2A gene mutations in NDD, and provide insights into their impact on PP2A structure and potential function in brain physiology and development.

\section{Structure of PP2A phosphatases}

The majority of PP2A holoenzymes are comprised of three subunits: a catalytic C, a scaffolding A and a regulatory B-type subunit, encoded by 19 different human genes (2 for C-, 2 for A- and 15 for B-subunits) [6] (Figure 1A). In addition, about one-third of PP2A species consists of an A and $C$ subunit only (core dimer) [7,8] (Figure 1A), or may in 
part be complexed to 'atypical' regulatory proteins, such as Galpha 12 [9] or subunits of the integrator complex $[10,11]$ (Figure 1B). These atypical interactors and the canonical B-subunits determine substrate specificity and regulation of the phosphatase complex $[6,10,12,13]$. In addition, catalytically inactive PP2A complexes have been described, which might exist in cells as stable intermediates of the multi-step process of PP2A holoenzyme biogenesis [14], or might be specifically formed from disassembled PP2A complexes during cell stress $[14,15]$. These intermediate PP2A complexes harbour stabilising PP2Abinding proteins such as alpha4, TIPRL1 (Target of rapamycin Pathway Regulator-Like 1) and the methyl esterase PME-1 (PP2A Methyl Esterase-1) (Figure 1B). Conversely, activating proteins, such as the PP2A methyl transferase LCMT1 (Leucine Carboxyl Methyl Transferase 1) and the ATP-dependent chaperone and isomerase PTPA (PP Two A Phosphatase Activator) are indispensable for the generation and assembly of active PP2A holoenzymes (Figure 1C) [14]. In addition, an increasing number of cellular PP2A inhibitory proteins has been described that inhibit phosphatase activity of (specific) PP2A trimers, thereby regulating their function in physiologic and pathologic conditions [1620] (Figure 1C). Finally, PP2A A- and some B-subunits can form atypical complexes with other Ser/Thr phosphatases, such as PP4 [21-24], PP5 [25,26] and PPM1G [27] (Figure 1D), further illustrating how integration of PP2A subunits into distinct cellular complexes may drive different cellular functions.

\section{Determinants of PP2A substrate specificity}

PP2A achieves substrate specificity in part by (i) tissue-specific expression of canonical or non-canonical regulatory subunits [12], (ii) by differences in the subcellular localisation of the regulatory subunits $[12,13]$, and (iii), as more recently demonstrated, by the presence of substrate docking motifs in some of the B-subunit families (B56 and B55) [28-35]. Specifically, for subunits of the B56 family, it was shown that they promote binding of the PP2A holoenzyme to cellular proteins harbouring a Short Linear Interaction Motif (SLiM), denoted as LxxIxE motif [28]. This motif is recognised by a surface-exposed hydrophobic pocket present in all B56 isoforms and can be found in a large number of cellular and viral proteins, typically in intrinsically disordered regions of those proteins [28-32]. These 
B56 interactors are postulated to be direct PP2A-B56 substrates, or act as scaffolds for anchoring PP2A-B56 substrates [28,33]. Recently, another conserved 'acidic patch' in B56 subunits was identified, mediating a more dynamic, electrostatic interaction with positively charged motifs located nearby the LxxIxE motif in a subset of B56 interactors [35]. In addition, B56 subunits directly seem to affect the dephosphorylation site preference of the PP2A catalytic subunit, resulting in unique patterns of kinase opposition [36,37], which are further modulated by affinity and position of the B56 binding motifs [37]. Finally, the PP2A-B56-shugoshin (Sgo1) co-crystal structure [38] revealed the presence of a third substrate binding mode of PP2A-B56, involving contacts between Sgo1 and both the B56 and the C subunit. A subset of these Sgo1-interacting B56 residues [38], specifically present in B56 $\gamma$ and $\delta$ isoforms, and not conserved in B56 $\alpha$ or $\varepsilon$ isoforms, underlie the different subcellular localisations and functions of these isoforms in mitotic cells [39] - providing the first insights into how substrate specificity and its regulation may differ between different isoforms of the same (B56) family.

Like B56, subunits of the B55 subunit family directly affect the dephosphorylation site preference of the catalytic subunit, showing a strong preference to dephosphorylate SerPro and Thr-Pro motifs, in the test tube and in cells $[34,40,41]$. In addition, B55 subunits recognise stretches of basic amino acids near the dephosphorylation site, further facilitating substrate docking $[34,41]$. Nevertheless, dephosphorylation of Ser-Pro and Thr-Pro sites is not a unique feature of PP2A-B55 complexes, as the INTAC complex, consisting of the PP2A core dimer and the 9-subunit Integrator complex, has recently been shown to dephosphorylate multiple Ser-Pro sites within the C-terminal domain of RNA polymerase II [10]. How both remaining B-type subunit families, B" and the striatins, dictate PP2A substrate specificity, remains unclear.

\section{PP2A subunit expression in brain}

Examination of RNA-seq data from different mouse tissues generated by the Mouse ENCODE consortium initiative [42] reveals PP2A subunits are highly expressed in the developing and adult brain (Figure 2A). Consistent with published data from human cells $[43,44]$, expression of the $\alpha$ isoforms of PP2A A (Ppp2r1a) and C (Ppp2ca) is generally 
much higher than expression of the $\beta$ isoforms of PP2A A (Ppp2r1b) and C (Ppp2cb), respectively, and moderately increases during brain development (Figure 2A). While overall expression of $\mathrm{B}^{\prime \prime}$-type subunits (Ppp2r3a and Ppp2r3c) and Strn is rather low in brain, all other regulatory B subunits are highly expressed, particularly $P p p 2 r 2 b$ and Ppp2r2c, Ppp2r5b and Ppp2r5d, and Strn4 (Figure 2A).

Moreover, B55 $\beta$ (Ppp2r2b) and B55ץ (Ppp2r2c) expression significantly rises during embryonic brain development (Figure 2A), with B55y further increasing after birth, and B55 $\beta$ decreasing again, consistent with published data from rat [45]. The same increased embryonic brain expression pattern is seen for zinedin (Strn4) and B56ß (Ppp2r5b) (Figure 2A). Interestingly, cellular studies in rat PC12 cells also showed increased B55 $\beta$, $\mathrm{B} 55 \mathrm{\gamma}$ and $\mathrm{B} 56 \beta$ (but not $\mathrm{C}, \mathrm{A}, \mathrm{B} 56 \alpha$ and $\mathrm{B} 568$ ) expression at the protein level upon neuronal growth factor (NGF)-induced neuronal differentiation [46]. Overexpression of $\mathrm{B} 55 \mathrm{\gamma}$ hereby facilitated neuritogenesis by stimulating the mitogen-activated protein kinase (MAPK) cascade downstream of the NGF-receptor and upstream of BRAF [46].

Although some caution in interpreting the data might be warranted (because of potential antibody specificity issues), examination of the Human Protein Atlas (www.proteinatlas.org) provides further insight into the spatial distribution of PP2A subunits in brain, with some subunits clearly clustering in defined brain sub-regions, and with the highest expression level differences found in the cerebellum (Figure 2B). In situ hybridisation and immunohistochemistry studies in rat and mouse brain have largely confirmed this wide distribution for the B55 subunits [45,47], the B56 subunits [48-51] and the striatins [52-54], although sometimes inconsistencies are seen between mRNA and protein distribution, which might derive from e.g. the use of antibodies recognising multiple isoforms of a single gene (summarised in Table 1).

At the cellular level, PP2A is primarily expressed in neurons, but is also found in glial cells, such as astrocytes [47,52] and oligodendrocytes [55]. Upon fractionation of brain tissue, the PP2A C subunit is generally distributed and found in most subcellular fractions, including the cytosol, nucleus, microtubules, neurofilaments, membranes and synaptosomes (post-synaptic densities) [56-58]. However, the B-subunits clearly show a 
more restricted subcellular localisation pattern (Table 1), suggestive for specific subcellular compartmentalisation of different PP2A holoenzymes within neural cells. Overall, the specific PP2A subunit expression patterns during brain development and within different adult brain areas, cell types and subcellular compartments clearly underscore the broad and diverse neurobiological PP2A functions.

\section{PP2A in mammalian brain function and development: in vivo studies}

Only few studies investigated the in vivo functions of PP2A (holoenzymes) in mammalian brain so far - the majority using genetically engineered mouse models [2].

Conditional knockout (KO) of Ppp2ca in the nervous system (Nestin-Cre or D6-Cre) resulted in severe microcephaly and cortical atrophy at post-natal day 7 (P7), characterised by loss of cortical neurons and decreased thickness of cortical layers II-V [59]. Animals performed poorly in a Morris water maze test, indicating learning and memory deficits. In C $\alpha$ KO neuronal progenitor cells (NPCs), upregulated Hippo signalling was found, witnessed by an increased phosphorylation of MST1/2 (Ser180/183), LATS1 (Ser909) and YAP1 (Ser127), and inhibited nuclear translocation of YAP1. Together with increased phosphorylation of p73 (Tyr99), this likely explains the increased apoptosis and diminished proliferation of these NPCs [59]. Of note, the inhibitory role of PP2A in Hippo signalling is mediated by the B"'/striatin subunits [60], and in Drosophila, increased B"' levels promote neuronal stem cell (NSC) reactivation to generate adult neurons and glia cells, while the $B 56 \alpha / \beta / \varepsilon$ subunit maintains NSC quiescence by suppressing Insulin receptor/AKT signalling [61]. Accordingly, expression of the PP2A-B56 inhibitor CIP2A (Cancerous Inhibitor of PP2A) in several mouse brain neurogenic regions promoted proliferation and self-renewal of mouse NPCs, while its expression dropped dramatically upon NPC differentiation [62]. In the chicken embryo, CIP2A promoted the induction and early specification of neural crest cells into NSCs at the neural plate, but not at a later stage, i.e. after neural tube closure [63].

The specific KO of Ppp2ca in NPCs of the dorsal telencephalon from embryonic day 10.5 (E10.5) onwards (Emx1-IRESCre) further underscored deficits in cortical development 
upon PP2A loss [64]. In embryos of these mice, the radial glial progenitors (RGPs; the major neural stem cells), showed ectopic expression outside of the ventricular zone, likely due to loss of intact adherens junctions which would normally anchor the apical processes of the RGPs onto the ventricular membrane. Moreover, while their proliferation was unaffected, their differentiation into late-born neurons was significantly impaired, contributing to the microcephaly phenotype observed at P0 [64].

The specific KO of Ppp2ca in hippocampus CA1 region (Camk2a-Cre) provided evidence for a role of PP2A in synaptic transmission and hippocampus-dependent memory [65]. Loss of Ppp2ca in CA1 did not affect basic locomotion and exploration abilities, nor memory formation, but impaired contextual fear memory extinction. This correlated with a decrease in synaptic efficiency, characterised by impaired high-frequency stimulationinduced long-term potentiation (LTP), impaired depotentiation, and impaired lowfrequency stimulation-induced long-term depression (LTD) [65].

A large number of brain-specific PP2A strains (transgenic and knockout) have underscored the role of PP2A, and particularly of PP2A carboxy-methylation, the PP2AB55 $\alpha$ and B55 $\gamma$ holoenzymes, and the PP2A inhibitors SET [66] and CIP2A $[67,68]$ in dephosphorylation of the microtubule-associated protein tau and its role in the pathogenesis of AD (reviewed in [2]). However, total Ppp2r2a (B55 $\alpha$ ) knockout proved embryonic lethal (post E10.5) with smaller B55a KO embryos displaying a variety of neural defects, including disorganised cortical layers, exencephaly, spina bifida and cranial vault collapse, as well as syndactyly and severe epidermal defects [69].

In contrast, $\mathrm{KO}$ of other PP2A regulatory subunit genes, e.g. Ppp2r2b, Ppp2r5a, Ppp2r5c, Ppp2r5d and Strn, did not appear to be essential for mammalian brain development [51,70-75]. Ppp2r2b KO mice, specifically deficient for the B55 32 isoform, showed normal motor-coordination, activity, learning and anxiety levels, but showed a markedly decreased susceptibility for cerebral ischemia and ischemic damage [70]. This was attributed to increased phosphorylation and inhibition of neuronal dynamin-related protein 1 (Drp-1), resulting in improved mitochondrial respiratory activity, $\mathrm{Ca}^{2+}$ homeostasis and attenuated superoxide production in response to ischemia [70]. Ppp2r5a gene-trapped mice appeared without any apparent brain dysfunction, but 
showed skin [71] and heart abnormalities [72]. Likewise, no brain abnormalities were reported in Ppp2r5c gene-trapped mice, which were obese and showed defects in heart development [73]. Ppp2r5d KO mice had intact learning and memory, despite some decreased motoric performances and increased sensory abilities [51]. Heterozygous Ppp2r5d gene-trapped mice showed a weakened pre-pulse inhibition (PPI), exemplified by an increased acoustic startle response. This correlated with glycogen synthase kinase$3 \beta$ (GSK-3 $\beta$ ) hyperphosphorylation (Ser9), and decreased phosphorylation of the GSK-3 $\beta$ substrate, KCNQ2, an M-type potassium channel protein [74]. As both genetic reduction and pharmacologic inhibition of KCNQ2 also attenuated PPI, this suggested a mechanism by which PP2A-B568 maintains KCNQ2 channel activity and, thereby, its sensorimotoric gating in the medial prefrontal cortex [74]. As determined through auditory brainstem response measurements, Strn KO mice showed progressive hearing loss that was attributed to degeneration of the outer hair cells in the middle and basal regions of the organ of Corti, and to aberrant ribbon synapse maturation [75].

Other mouse studies focussed on the role of specific PP2A regulators in brain function or development. Conditional neuronal KO of Igbp 1, encoding the PP2A biogenesis regulator alpha4, did not result in any brain developmental defects, but impaired learning and memory, correlating with increased activity of CaMKIla [76]. The PP2A inhibitor SET (Suvar/Enhancer of zeste/Trithorax) was shown to regulate intrinsic axon regeneration capacity in mouse neurons [77]. Nuclear SET hereby clearly suppressed neurite/axon growth via transcriptional regulation, while membrane-associated SET promoted neurite growth in vitro and axon regeneration in vivo through a local inhibition of PP2A [77]. In utero electroporation studies of RGPs in the cortex of E13.5 mouse embryos revealed an important role of SETBP1 (SET Binding Protein 1), a SET stabilising protein, in neuronal migration, the establishment of proper cortical morphology and the projection of neurons through the corpus callosum [78]. The PP2A-B56-specific inhibitor BOD1 (Biorientation Of chromosomes in cell Division 1) showed a synaptic localisation in mouse neurons, and its deletion in Drosophila post-mitotic neurons resulted in abnormal synapse morphology and learning deficits [79]. The constitutive total-body KO of Cip2a in mice remained without any discernible phenotype in brain [80]. 
Finally, many studies focused on the role of brain PP2A in dopaminergic signalling and its regulation by CAMP and its main effector, PKA (CAMP-stimulated Protein Kinase) (reviewed in [81]). CAMP regulation of brain PP2A mainly impinges on the B56 subunit (that becomes phosphorylated, and thereby, activated by PKA) and the PP2A inhibitors ARPP-16/19 and ENSA (that lose their PP2A inhibitory potential upon their phosphorylation by PKA) [81]. Disinhibition of PP2A-B55 $\alpha$ and PP2A-B56 $\delta$ (and potentially other trimers) in a neuron-specific KO mouse of Arpp16 (CamKIla-Cre) significantly altered dopamine signalling in the striatum: mice showed increased motivation to respond to food reinforcement and decreased locomotor response to acute cocaine exposure. These phenotypes were associated with decreased basal phosphorylation of DARPP-32 (Thr57) and AKT kinase (Thr308), and a loss of forskolininduced increase in ERK1 phosphorylation (Thr202) in striatal slices [82].

\section{De novo PP2A gene mutations as novel genetic causes of neurodevelopmental delay}

Recently, we and others reported mono-allelic de novo mutations of specific PP2A genes (Table 2, Table 3) as novel genetic causes of intellectual disability (ID) and (neuro)developmental delay (NDD), associated with hypotonia, variable degrees of epilepsy, brain malformation (macrocephaly or microcephaly, ventriculomegaly (VM), corpus callosum (CC) hypoplasia/agenesis, impaired myelination) and facial dysmorphism [83-95]. Some patients also exhibit growth abnormalities (overgrowth), hearing and visual impairments, and heart problems [83-95]. Although a new group of developmental disorders and still rare, PP2A dysfunction is among the more common causes of ID/DD, with an estimated prevalence of $0.6-1.9 \%$ in the moderate-to-severe ID group without pathogenic copy number alterations [84]. By now, we are aware of approximately 300 cases worldwide, based on published studies and data from the Jordan's Guardian Angels Foundation (https://jordansguardianangels.org/), an international charity and family network, advocating for individuals affected by these rare disorders.

PPP2R5D, PPP2R5C and PPP2R5B-related disorders 
By far the largest number of PP2A regulatory B subunit mutated cases harbour mutations in PPP2R5D, encoding the regulatory B568 subunit [84-91] (Table 2). The PPP2R5Drelated disorder, termed MRD35 (mental-retardation-dominant-type 35) in the OMIM database (MIM: 616355), is characterised by mild to severe NDD, macrocephaly, pronounced hypotonia with severe delay in gross motor skills, speech impairment, autistic traits and commonly seizures [96]. All but one of the biochemically characterised

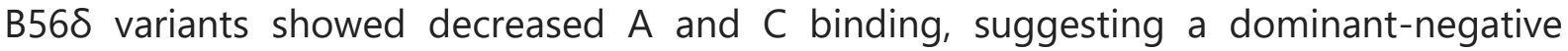
mode-of-action involving substrate 'trapping' [84]. PPP2R5C (encoding B56y) and PPP2R5B (encoding B56 3 ) are other PP2A genes associated with ID and overgrowth [85], each reported in just a single patient so far (Table 2). Although not yet biochemically characterised, the PPP2R5C and PPP2R5B variants are affected in the same, highly conserved acidic loop that is recurrently mutated in PPP2R5D-affected individuals (Figure 3). In B56 3 , this loop supposedly determines substrate recognition, mediating binding of tyrosine hydroxylase $(\mathrm{TH})$ to $B 56 \beta$ [97]. Structural data from the PP2A-B56y1 holoenzyme [98] indicates this loop connects $\alpha$-helices 3 and 4 of HEAT-repeat 2 (HR2) of B56 1 and mediates a direct contact between B56 1 and the $C$ subunit through its top residue, corresponding to E198 in B568 (Figure 3). This may explain why the E198K charge-reversing substitution (the most recurrent $P P P 2 R 5 D$ variant) results in the largest C-binding impairment, and substitutions in the rest of the acidic loop and in the helices at the bottom of the loop (Figure 3) affect C-binding considerably less (Table 2). Notably, although C subunit binding is impaired, none of the acidic loop variants completely abolished holoenzyme formation, potentially hinting at another mechanism, whereby the variants may affect PP2A-B56 substrate specificity by regulating substrate access to the $C$ subunit. In this scenario, the acidic loop within the p.E198K variant may be a lot less effective in shielding access of the substrate to the $C$ subunit active site, resulting in a gain-of-function mechanism. This, however, remains to be further clarified. Of the three other reported B568 variants, one (p.E250K) affects a conserved region immediately downstream of the SLiM-binding domain in the primary amino acid sequence that forms the intra-helical loop of HR3 and is in close contact with the acidic loop and the C subunit (Figure 3); one (p.E420K) affects the second helix of HR7, a 
conserved region in all B56 isoforms, of which the precise function is unclear (Figure 3); and another (p.P53S) is uniquely present in the specific N-terminal domain of the B56 isoform (and is hence not present in any of the known B56 crystal structures). While the p.P53S variant showed normal A/C binding [84], p.E420K exhibited a mild A/C subunit binding defect and decreased phosphatase activity measured on DiFMUP (6,8-Difluoro4-Methylumbelliferyl Phosphate) as a substrate [99]. How the p.E250K variant might be biochemically impaired remains to be determined, although an A/C-binding defect seems likely.

The first functional or downstream consequences of PPP2R5D mutation were recently described for the p.E420K variant in HEK293 cells [99]. Unbiased quantitative proteomic and phospho-proteomic analyses of heterozygous and homozygous E420K knockin (KI) cells revealed heterozygous-dominant changes in kinase/phosphatase signalling. Particularly, AKT-mTOR signalling was constitutively activated in p.E420K-expressing cells, correlating with increased cell size and an increased representation of phospho-peptides containing the $A G C$ kinase consensus motif $(R-x-R-x-x-S / T-B$, where $x$ represents any amino acid and B represent amino acids with a hydrophobic R-group) [99]. Interestingly, addition of rapamycin, a pharmacologic inhibitor of mTOR1, reduced cell size and phospho-S6 levels, but not phospho-AKT or phospho-GSK-3 $\beta$, suggesting the p.E420K variant would affect signalling upstream of mTOR1 [99]. In this respect, a clear association between AKT1 and PP2A-B56 or the p.E420K variant was found, suggesting AKT as the major PP2A-B568 substrate. Although still speculative, upregulated AKTmTOR signalling may contribute to the macrocephaly phenotype seen in all three reported E420K cases [86].

Epilepsy seems another major risk in the PPP2R5D-related disorder, although not all reported cases suffer from it (Table 2) and the observed seizure types are highly diverse [96]. Although the molecular basis for this is still unknown, PP2A-B568 plays a key role in nuclear targeting of the calcium channel subunit CACNB4 through a direct interaction [100]. Interestingly, PP2A-B568 binding was lost in mutated CACNB4 with a variant associated with juvenile myoclonic epilepsy [100], perhaps advocating to check the integrity of CACNB4 binding to PPP2R5D variants as well. 
Although the natural history of the PPP2R5D-related syndrome remains unclear, five adult cases (with variants p.E198K, p.E200K and p. E250K) were recently reported with signs of early-onset Parkinsonism [89-91]. Noteworthy was the reduced uptake of dopamine in the basal ganglia, the presence of severe substantia nigra atrophy and the absence of Lewy body or $\alpha$-synuclein pathology. Both PP2A-B56 $\beta[49,97]$ and PP2A-B56 [101] have been shown to regulate TH dephosphorylation/inactivation (B568: Ser40) and thus decrease dopamine synthesis. Conversely, PP2A-B568 is also a clear target of dopamine signalling, as it becomes phosphorylated by PKA on Ser573 within its Cterminal domain [102]. This phosphorylation promotes substrate affinity and catalytic efficiency, while leaving A/C binding unaffected [102]. In striatal dopaminergic neurons, the PP1 inhibitor DARPP-32 is a major PP2A-B56 substrate regulated that way [102]. However, it is unclear whether TH or DARPP-32 dysregulation might contribute to the pathogenesis of PPP2R5D-related disorders, or whether PP2A-B568 regulation by PKA might be altered in the $P P P 2 R 5 D$ variants. Other age-related neurodegenerative comorbidities might also be of relevance, given that Ppp2r5d KO mice develop progressive tauopathy with increased phosphorylation of tau but without neurofibrillary tangle formation in the hindbrain and brainstem [51]. The latter might also contribute to Parkinson's disease [103]. Finally, increased susceptibility for cancer development is a theoretical risk given the increased incidence of spontaneous cancer development in Ppp2r5d KO mice, mainly of hepatocellular carcinomas and hematologic malignancies $[104,105]$. So far, there are however no clinical indications suggesting increased cancer incidence in PPP2R5D-related NDD.

\section{PPP2R1A-related disorder}

De novo mutations in PPP2R1A, encoding the scaffolding A $\alpha$ subunit, have recently been extended to 37 cases [84,92-94] (Table 3). The PPP2R1A-related disorder, also termed MRD36 (MIM: 616362), exhibits a heterogeneous clinical presentation, with at least two distinguishable phenotypic and biochemical subgroups [92]. Common features are hypotonia and developmental delay (DD), usually in the intellectual disability (ID) range. The least severely affected subgroup encompasses variants in HEAT-repeats HR4 (p.F141l) and HR5 (p.T178N/S, p.M180T/V/K/R) and is characterised by ID/DD with a 
tendency for large head circumference (macrocephaly), absence of seizures and, in some cases, microtia and hearing loss (Table 3). Biochemically, these variants show normal B55 and $\mathrm{B}^{\prime \prime \prime}$ binding, severely decreased binding to all B56 subunits except B568, and variable binding defects to $B "$ subunits (Table 3). The more severely affected subgroup consists of different variants in HEAT-repeats HR5 (p.P179L, p.R182W, p.R183W/Q), as well as variants in HR6 (p.S219L, p.V220M) and HR7 (p.R258S/H), and is characterised by moderate to severe ID, tendency for small head circumference (microcephaly), a long face, seizures and corpus callosum hypoplasia/agenesis. In these cases, B55 binding was always severely impaired and correlated with a tendency for increased B"' binding (except for p.P179L); B56 and B" subunits showed more variable binding defects, while B56 binding was always retained (Table 3). Notably, variants from this subgroup are recurrently present in COSMIC (http://cancer.sanger.ac.uk/cosmic) and thus somatically found in tumours, with highest frequency in endometrial cancers [106]. Although in one case (PPP2R1A p.S219L), a benign tumour (lipoblastoma) was found at a very young age (1y) [92], it remains to be established whether an increased cancer risk is part of the clinical picture of this PPP2R1A-affected subgroup. Ectopic expression of $\mathrm{p} . \mathrm{R} 183 \mathrm{Q}$ in a uterine cancer cell line increased anchorage-independent growth and tumour formation, correlating with increased AKT and mTOR/p70-S6 signalling, but decreased ERK pathway activation [107]. On the other hand, expression of p.R183W in a colon cancer cell line or shp16-shp53-Myc/RAS epithelial cells (M/R cells) did not affect growth and correlated with increased ERK signalling [108] - indicating potential variant- and context-dependent signalling alterations.

One PPP2R1A-affected case showed a very mild phenotype with ASD and mild learning problems (full scale IQ of 86 ) and no hypotonia, consistent with a normal biochemical profile of the associated p.S152F variant (Table 3) [92]. Nevertheless, ectopic expression of p.S152F in primary neurons resulted in fewer dendritic spines compared to WT A $\alpha$ expressing neurons, indicative for an altered functionality [92]. Mapping of the pathogenic A $\alpha$ variants on the PP2A-B56y1 crystal structure (Figure 4) further revealed that all, except p.S152F and p.I32M, clustered on one side of the horseshoe-shaped A $\alpha$ molecule in or around the intra-helical repeat loops of HR4, HR5, HR6 or HR7 that 
constitute the binding interfaces with regulatory B subunits (Figure 4A). Nevertheless, it seems that different B-type subunits critically depend on integrity of different HRs, and even specific amino acids within a given $H R$, to retain $A \alpha$ binding (Figure 4B) [92]: for B55, these are HR4, HR5 and HR6; for B56 (except B568), these are HR4 and HR5 and for some isoforms, HR6; for $B^{\prime \prime}$, these are HR4 and HR7 and some residues within HR5; for $\mathrm{B}^{\prime \prime \prime}$, binding is entirely independent of HR4-HR7 but mainly occurs via the intra-helical repeat loop of HR1, as recently demonstrated [60]. The structural basis for the retained binding of $B 56 \delta$ to all pathogenic $A \alpha$ variants remains to be determined but might involve contributions of its specific $\mathrm{N}$ - or C-terminal domains.

Although $C$ subunit binding occurs through HEAT-repeats HR10-HR15 (Figure 4A), several A $\alpha$ variants show impaired C binding, which remarkably inconsistently correlates with associated PP2A activity (Table 3). The reason for this is currently unclear, although activity of different mutant A $\alpha$-containing trimers may be differentially affected, and increased binding of the PP2A inhibitor TIPRL1 to some mutant A $\alpha$-containing trimers has been reported (particularly to PP2A-B568) [107].

In conclusion, consistent with the larger apparent impact of A $\alpha$ missense variants on the PP2A system as a whole, the PPP2R1A spectrum is clearly wider than the PPP2R5Drelated disorder - ranging from mild to severe clinical presentations, and correlating with different specific PP2A holoenzyme assembly and activity deficiencies - presumably caused by both loss- and gain-of-function mechanisms, or even combinations thereof.

\section{PPP2CA-related disorder}

So far, sixteen individuals with variants in PPP2CA, encoding the $C \alpha$ subunit, have been reported [95]. The PPP2CA-related disorder, also called NEDLBA (neurodevelopmental disorder and language delay with or without structural brain abnormalities, MIM: 618354), has a heterogeneous clinical presentation, characterised by mild to profound ID/DD, ASD and seizures (each in about half of the cases), brain abnormalities (CC hypoplasia, dilated ventricles, delayed myelination in some cases; two cases with macrocephaly and five with microcephaly), and mild or no facial dysmorphism (Table 3). The identified variants were dispersed throughout the $C$ structure (Figure 5), and only one recurrent variant (p.H191R) and one recurrently affected amino acid (D223; variants 
p.D223H and p.D223V) were reported [95]. Functional characterisation of the variants revealed mainly loss-of-function (LoF), consistent with both haploinsufficiency (for milder cases) as well as dominant-negative disease mechanisms (for more severe cases). Some mutations indeed resulted in a complete null allele (p.F146fs, p.Q125*, p.R214*, partial gene deletion), while others resulted in expression of $\mathrm{C} \alpha$ variants with significantly impaired phosphatase activity but retained binding to the A subunit and specific B-type subunits (Table 3). Overall, the PPP2CA-related disorder is the least 'recognisable' of the PP2A ID/DD syndromes.

\section{Disorders related to mutation of genes encoding cellular PP2A regulators}

Although a clear causal link with PP2A dysregulation has not (yet) been formally established, mutations of specific PP2A regulator encoding genes can also result in disorders characterised by intellectual disability and (neuro)developmental delay (Table 4). De novo mutations in SET, encoding the PP2A inhibitory protein SET, were reported in 8 cases $[83,109,110]$. The SET-related disorder (also called MRD58 or MIM: 618106) is characterised by mild ID/DD and mild facial dysmorphism, and most variants are predicted to be loss-of-function [109]. LoF is also the likely mechanism in 13 cases exhibiting nonsense mutations in SETBP1, encoding the SET stabilising protein SETBP1 [111]. This SETBP1-related disorder, known as MRD29 or MIM: 616078, is characterised by mild to severe ID, delayed speech and motoric skill development, facial dysmorphism (long face, characteristic eyebrows), and often seizures [111]. In contrast, de novo gain-offunction (GoF) mutations of SETBP1 result in Schinzel-Giedion syndrome (SGS; MIM: 269150), a much more severe condition that affects many other organs besides brain [112-114]. At least 53 individuals have been reported expressing a SETBP1 variant affected in or nearby the DSGIGT (868-873) degron, resulting in increased SETBP1 stability [112-114]. Expression of the p.G870S SETBP1 variant in RGPs of the developing mouse brain results in severe impairment of neuronal migration, cortical architecture and CC development [78]. SGS patients suffer from severe ID/DD, have distinctive craniofacial features (mid-face retraction, bi-temporal narrowing, frontal bossing, hypertelorism, short upturned nose, low-set abnormal ears), seizures, microcephaly (75\%), CC agenesis, genitourinary and renal malformations, cardiac defects (50\%), and an increased cancer 
risk [112-114]. One variant (p.D269V) has been reported in CIP2A, as a novel DandyWalker variant, giving rise to severe ID, speech and motoric delay and characteristic brain abnormalities (hypoplasia of the vermis, enlarged fourth ventricle, atrophy of the pons, mild atrophy of the midbrain and normal posterior fossa) [115]. Although the functional characterisation of this CIP2A variant was rather poor, a gain-of-function was suggested [115]. Finally, two homozygous nonsense variants (p.R112* and p.R151*) in BOD1 were reported in two independent consanguineous families, causally linked to moderate ID, mild facial dysmorphism, hearing impairment and endocrine abnormalities $[79,116]$.

\section{Therapeutic opportunities?}

Since the large majority of clinical symptoms of the PP2A ID/DD syndromes cannot yet be molecularly explained, it is currently difficult to envisage therapeutic strategies based on rational insights. Nevertheless, PP2A syndromes may be amongst the treatable causes of genetic disorders because disturbed brain function, and not brain development, seem to be the main problem. In particular, a potential benefit of pharmacologic kinase inhibitors could be considered impacting on affected PP2A substrates, e.g targeting the PI3K-AKT-mTOR pathway that was shown to be overactive in PPP2R5D E420K KI cells [99] as well as in HEC-1A cells overexpressing PPP2R1A p.R183Q [107]. In addition, recently developed pharmacologic PP2A activators and inhibitors, many of which have the ability to cross the blood-brain-barrier [117], and some of which even modulate activity of specific PP2A holoenzymes [118-120] could become of future therapeutic relevance.

\section{Perspectives}

- PP2A-related DD/ID are rare disorders, so far mainly affecting PPP2R5D, PPP2R1A and PPP2CA, which clearly illustrates the important role of PP2A in brain function and development. However, more cases/variants and biochemical studies are needed to provide additional insights into the pathogenic mechanisms, in particular whether specific variants may act in a dominant-negative way, as loss-of-function variants, or rather through a gain-of-function mechanism. It also remains to be determined to what 
extent specific variants, within a single affected gene or affecting different PP2A subunit or inhibitor genes, may impact on common signalling pathways, or whether variantspecific differences may exist.

- PP2A-B56 dysfunction is particularly involved in PP2A-related DD/ID, and there is immediate need for further deciphering PP2A-B56 crystal structure, phospho-regulation and function in order to understand the impact of different PP2A mutations on these properties.

- Generation and characterisation of relevant disease models is eagerly awaited, not just to provide insights into the molecular pathogenesis of PP2A syndromes, but also for use as pre-clinical test models for PP2A-directed or kinase-targeted therapeutics. 


\section{Figures and tables}

\section{Figure legends}

Figure 1: Structural arrangement of PP2A holoenzymes, and main cellular regulators.

A. Canonical PP2A complexes consist of at least a catalytic $C$ subunit ( $\alpha$ or $\beta$ isoform, encoded by PPP2CA or $C B$ ) and a structural $A$ subunit ( $\alpha$ or $\beta$ isoform, encoded by PPP2R1A or R1B), which together constitute the PP2A core dimer. PP2A heterotrimers consist of a core dimer bound to a regulatory B-type subunit, which belongs to one of four families $\left(B, B^{\prime}, B^{\prime \prime}\right.$ or $\left.B^{\prime \prime \prime}\right)$ and are encoded by 15 different human genes (PPP2R2A to $R 2 D, P P P 2 R 3 A$ to $R 3 C, P P P 2 R 5 A$ to $R 5 E$, and PPP2R6A to $R 6 C$; (alternative) protein names of the four B subunit family members are shown between brackets). Additional B-type subunit diversity is created by alternative splicing of some of these regulatory $B$ subunit encoding genes, or by alternative translation of some deriving mRNAs. B. Besides these PP2A holoenzymes, several non-canonical PP2A complexes have been described exhibiting phosphatase activity towards specific cellular protein substrates, exemplified by the INTAC complex (=PP2A core dimer bound to 9 subunits of the Integrator complex) and a complex between the core dimer and the Galpha 12 protein. In addition, several catalytically inactive PP2A complexes are known to exist in cells, e.g. harbouring TIPRL1 (encoded by TIPRL), alpha4 (IGBP1) or PME-1 (PPME1). C. PP2A activators PTPA (PP2A activator, encoded by PPP2R4) and LCMT1 (PP2A Leucine Carboxyl Methyl Transferase 1, encoded by LCMT1) perform indispensable functions in promoting assembly of active PP2A holoenzymes, while an increasing number of cellular PP2A inhibitory proteins inhibit phosphatase activity of (specific) PP2A trimers. D. Some canonical PP2A regulatory B-type subunits form functional complexes with other phosphatases, including the PP2A-like phosphatases PP4 and PP5, and the PP2C-like phosphatase PPM1G.

Figure 2. Expression of PP2A subunit genes in brain.

A. Expression of PP2A genes in mouse brain as determined by RNA-seq by the Mouse ENCODE consortium initiative $(n=2)$ [42]. The Mouse ENCODE dataset was queried through the NCBI Gene database (www.ncbi.nlm.nih.gov/gene), exported to Excel, and 
displayed as a heat map, with green indicating highest expression, and red indicating lowest expression. Numbers denote 'the number of reads per kilobase per million reads placed' (RPKM). Data for Ppp2r3d were absent in this dataset. B. Expression of PP2A subunits in human brain according to Human Protein Atlas data. Data were obtained from the Consensus Human Brain dataset, clustering and displayed as a heat map using Clustvis software. Blue denotes low expression, red denotes high expression.

Figure 3. Mutation hotspots in PPP2R5D, $P P P 2 R 5 C$ and $P P P 2 R 5 B$-related disorders.

A. Most identified PPP2R5D variants (in green), and the single identified PPP2R5C (green underlined) and PPP2R5B (green italics underlined) variants are affected in a conserved acidic loop (1), present in all B56 isoforms, that directly faces the $C$ subunit. Another affected PPP2R5D region harbouring E250 (2) is located just downstream of the SLiMbinding domain (4), and is fully conserved in all B56 members. Residues within the SLiM-binding domain predicted to be involved in substrate binding are indicated in light blue (numbering according to B56 1 ). The third affected region in PPP2R5D is a conserved helix that harbours the E420 residue (3). The structure was generated based on PP2A-B56y1 crystallographic data, using PDB code 2IAE [98] and Molsoft MolBrowser 3.9-2b software (ICM-Browser-Pro). The PP2A C subunit is shown in dark blue, the A subunit in yellow and the B56y1 subunit in red. B. Level of conservation amongst all B56 isoforms of residues in the three affected regions of PPP2R5D. Mutated residues in red; conserved residues in blue; non-conserved residues in black.

Figure 4. Mutation hotspots in PPP2R1A-related disorders.

A. Localisation of A $\alpha$ variants (in red) within HEAT-repeats, HR1, HR4, HR5, HR6 and HR7, with intrarepeat loop residues highlighted in purple. All but two variants (p.I32M and p.S215F) cluster at the same side of the horseshoe, which constitutes the interface with the regulatory B-type subunits (as seen in the inset). The structure was generated based on PP2A-B56y1 crystallographic data, using PDB code 2IAE [98] and visualised with Molsoft MolBrowser 3.9-2b software (ICM-Browser-Pro). The PP2A C subunit is shown in dark blue, the A subunit in yellow and the B56y1 subunit in red. B. Overview of necessary binding interfaces of different PP2A B-type subunits to the intra-helical repeats of HR4, HR5, HR6 and HR7 of A $\alpha$, based on biochemical analyses of PPP2R1A variants [92] and 
complementary to crystal structure data. Binding of B55 $\alpha$ is most dependent on binding contacts with intra-helical loops of HR5, HR6 and HR7, while B56 isoforms, except B56ठ, predominantly bind to intra-helical loops of HR4 and HR5, and to a lesser extent, of HR6. Binding of PR72 requires contacts within intra-repeat loops of HR4, HR5 and HR7. B56 seems unique in its $A \alpha$ binding behaviour, being unaffected by single amino acid changes in any of the intra-repeat loops of HR4-HR7. STRN3 binding does not occur via HRs 4-7, but rather via HR1 [60].

Figure 5. Distribution of affected amino acids in PPP2CA-related disorders.

Missense variants within the C $\alpha$ subunit (p.G60V, p.D88G, p.Q122H, p.Y127C, p.D131H, p.H191R, p.D223H, p.D223V, p.Y265C) are indicated in red; truncation mutants (p.Q125*, p.R214*, p.R295*) in green; and insertion mutants (p.F308dup) in purple. The structure was analysed based on PP2A-B56y1 crystallographic data, using PDB code 2IAE [98] and visualised with Molsoft MolBrowser 3.9-2b software (ICM-Browser-Pro). The PP2A C subunit is shown in dark blue, the A subunit in yellow and the B56y1 subunit in red. 


\section{Tables}

Table 1: Expression of PP2A regulatory B subunit genes in brain: distribution, cell type and subcellular localisation. C: cytosol, CA: cornu ammonis; CK: cytoskeleton, DG: dentate gyrus; M: membranes, N: nucleus, n/a: not analysed

\begin{tabular}{|c|c|c|c|}
\hline Gene & Subcellular protein localisation & Brain cell type and brain region expression & Ref. \\
\hline $\begin{array}{l}P P P 2 R 2 A \\
B 55 \alpha\end{array}$ & $\begin{array}{l}\mathrm{C}, \mathrm{N}>\mathrm{M}>\mathrm{CK} \\
\text { In cerebellar neurons: in the soma }(\mathrm{C}, \mathrm{N}) \text {, } \\
\text { not in the dendrites; in cortical and } \\
\text { hippocampal neurons: also in dendrites } \\
\text { Associated with microtubules }\end{array}$ & $\begin{array}{l}\text { *mRNA: throughout; high in striatum } \\
\text { *Protein: in neurons and activated astrocytes; high in striatum } \\
\text { (large, and small-to-midsize neurons), CA1<CA2-CA4, cortex } \\
\text { (highest in layer V, Purkinje cells, stellate and basket cells), } \\
\text { globus pallidus, thalamus, hypothalamus, midbrain, hind brain }\end{array}$ & {$[45,47,58]$} \\
\hline $\begin{array}{l}P P P 2 R 2 B \\
B 55 \beta\end{array}$ & $\begin{array}{l}\mathrm{C}>\mathrm{M}, \mathrm{CK} \\
\text { In cerebellar neurons: in the soma }(\mathrm{C}), \\
\text { dendrites and axons; in cortical and } \\
\text { hippocampal neurons: less in dendrites }\end{array}$ & $\begin{array}{l}\text { *mRNA: throughout; low in cerebellum } \\
\text { *Protein: only in neurons; low in cerebellum, high in striatum } \\
\text { (only in large neurons), CA1<CA2-CA4, cortex (highest in layer } \\
\text { V, Purkinje cells), globus pallidus, thalamus, hypothalumus, } \\
\text { midbrain, hindbrain }\end{array}$ & {$[45,47]$} \\
\hline $\begin{array}{l}P P P 2 R 2 C \\
B 55 Y\end{array}$ & $\mathrm{CK}>\mathrm{M}, \mathrm{C}$ & $\begin{array}{l}\text { *mRNA: throughout except in brainstem, high in olfactory bulb } \\
\text { *Protein: throughout; high in hindbrain }\end{array}$ & {$[45,47]$} \\
\hline $\begin{array}{l}P P P 2 R 2 D \\
B 55 \delta\end{array}$ & $\mathrm{n} / \mathrm{a}$ & $\begin{array}{l}{ }^{*} \text { mRNA: throughout, high in cerebellum } \\
\text { *Protein: } n / a\end{array}$ & {$[47]$} \\
\hline $\begin{array}{l}P P P 2 R 5 A \\
B 56 \alpha\end{array}$ & $\mathrm{n} / \mathrm{a}$ & $\begin{array}{l}{ }^{*} \text { mRNA: highest in brainstem, lower in cerebellum and olfactory } \\
\text { bulb, lowest in cortex and hippocampus } \\
\text { *Protein: } n / a\end{array}$ & [48] \\
\hline $\begin{array}{l}P P P 2 R 5 B \\
B 56 \beta\end{array}$ & $\begin{array}{l}\text { In dopaminergic and noradrenergic } \\
\text { neurons: in the soma and dendrites, } \\
\text { undetectable in axons and presynaptic } \\
\text { terminals }\end{array}$ & $\begin{array}{l}\text { *mRNA: high expression throughout, highest in hippocampus } \\
\text { (CA1, CA3 > DG), cortex (uniform in II-V) and olfactory bulb; } \\
\text { moderate in brainstem and cerebellum } \\
\text { *Protein: widely expressed in neurons throughout, virtually }\end{array}$ & {$[48,49]$} \\
\hline
\end{tabular}




\begin{tabular}{|c|c|c|c|}
\hline & & absent in glial cells & \\
\hline $\begin{array}{l}\text { PPP2R5C } \\
\text { B56Y }\end{array}$ & $\begin{array}{l}\text { In cortical neurons: predominantly in } \mathrm{N} \text {, } \\
\text { perinuclear area, and at the base of the } \\
\text { cellular processes, absent from axons }\end{array}$ & $\begin{array}{l}\text { *mRNA: highest in cerebellum and brainstem, low in cortex and } \\
\text { hippocampus, absent in olfactory bulb [48]; high expression in } \\
\text { cortex, hippocampus, olfactory bulb and thalamus; low } \\
\text { expression in cerebellum, striatum and corpus callosum [50] } \\
\text { *Protein: exclusively in neurons, absent form astrocytes and } \\
\text { oligodendrocytes }\end{array}$ & {$[48,50]$} \\
\hline $\begin{array}{l}P P P 2 R 5 D \\
\text { B56ठ }\end{array}$ & $\begin{array}{l}\text { In neurons: mostly in } \mathrm{C} \text {, weak in } \mathrm{N} \text { and } \\
\text { dendrites }\end{array}$ & $\begin{array}{l}\text { *mRNA: highest in hippocampus (CA1 > CA3, DG), moderate in } \\
\text { cortex and olfactory bulb, low in brainstem and cerebellum } \\
\text { *Protein: in neurons; highest expression in striatum and } \\
\text { thalamus; intermediate expression in brainstem and } \\
\text { hippocampus; weakest expression in cortex and cerebellum }\end{array}$ & {$[48,51]$} \\
\hline $\begin{array}{l}P P P 2 R 5 E \\
\text { B56ع }\end{array}$ & $\mathrm{n} / \mathrm{a}$ & $\begin{array}{l}{ }^{*} \text { mRNA: highest in cortex; moderate in hippocampus, brainstem } \\
\text { and cerebellum; weak in olfactory bulb } \\
\text { *Protein: } n / a\end{array}$ & {$[48]$} \\
\hline $\begin{array}{l}\text { STRN } \\
\text { striatin }\end{array}$ & $\begin{array}{l}\text { In neurons: in somatodendritic } \\
\text { compartment ( } C \text { and } M) \text {, especially in } \\
\text { dendritic spines }\end{array}$ & $\begin{array}{l}\text { *mRNA: in cerebrum < cerebellum } \\
\text { *Protein: in basal ganglia, cranial and spinal motor nuclei; high } \\
\text { expression in striatum, olfactory tubercules, red nucleus, } \\
\text { subthalamic nucleus and cranial nerve motor nuclei }\end{array}$ & [52] \\
\hline $\begin{array}{l}\text { STRN3 } \\
\text { SG2NA }\end{array}$ & $\begin{array}{l}\text { In Purkinje cells and hippocampal } \\
\text { neurons: only in } \mathrm{C} \text {, not N; only in } \\
\text { dendrites, not axons; highest density in } \\
\text { dendritic spines of excitatory synapses }\end{array}$ & $\begin{array}{l}\text { *mRNA: in cerebrum > cerebellum } \\
\text { *Protein: in neurons and glial cells (astrocytes in white matter); } \\
\text { strong staining in cerebellum (Purkinje cells, Golgi cells), } \\
\text { striatum (large aspiny interneurons) and hippocampus } \\
\text { (pyramidal and granular cells) }\end{array}$ & {$[52,53]$} \\
\hline $\begin{array}{l}\text { STRN4 } \\
\text { zinedin }\end{array}$ & $\begin{array}{l}\text { In neurons: in somatodendritic } \\
\text { compartment, enriched in dendritic }\end{array}$ & $\begin{array}{l}\text { *mRNA: in cerebrum = cerebellum } \\
\text { *Protein: highest expression in hippocampus, cortex (all layers), }\end{array}$ & {$[52,54]$} \\
\hline
\end{tabular}


Table 2: Overview of PP2A B-type subunit encoding genes harbouring de novo mutations, causally related to the aetiology of (neuro)developmental disorders. RNA transcripts for PPP2R5D: NM_006245.3; PPP2R5C: NM_001161725 and PPP2R5B: NM_006244. ADHD: attention deficit and hyperactivity disorder; ASD: autism spectrum disorder; CC: corpus callosum; DD developmental delay; ID: intellectual disability; n/a: not analysed.

\begin{tabular}{|c|c|c|c|c|}
\hline variant & Biochemical dysfunction & Clinical description & $\mathbf{n}^{\circ}$ cases & Ref. \\
\hline p.E197K & $n / a$ & Moderate ID, DD, macrocephaly, hypotonia & 1 & [86] \\
\hline p.E200K & $\mathrm{A} / \mathrm{C}$ binding moderately impaired & $\begin{array}{l}\text { Mild ID, no seizures, hypotonia, macrocephaly } \\
\text { Early-onset }(22 \text { y.) parkinsonism, mild ID, no seizures, } \\
\text { overgrowth, hypotonia } \\
\text { ID/DD, hypotonia, ASD } \\
\text { Early-onset ( } 27-40 \text { y.) parkinsonism, mild ID, no seizures }\end{array}$ & $\begin{array}{l}2+1 \\
1 \\
1 \\
2\end{array}$ & $\begin{array}{l}{[84,85]} \\
{[85,89]} \\
{[86]} \\
{[89]}\end{array}$ \\
\hline p.W207R & $\mathrm{A} / \mathrm{C}$ binding moderately impaired & moderate ID/DD, hypotonia, no seizures, & 1 & [84] \\
\hline
\end{tabular}




\begin{tabular}{|c|c|c|c|c|}
\hline p.E250K & $\mathrm{n} / \mathrm{a}$ & $\begin{array}{l}\text { Moderate ID, DD, macrocephaly, ADHD, auditory } \\
\text { processing disorder, early-onset parkinsonism (20 y.) }\end{array}$ & 1 & [90] \\
\hline p.E420K & $\begin{array}{l}\text { A/C binding mildly impaired; } \\
\text { downstream: increased mTOR-AKT } \\
\text { signalling (HEK293 cells) }\end{array}$ & $\begin{array}{l}\text { Severe ID/DD, macrocephaly, hypotonia, ASD (2/3), } \\
\text { enlarged ventricles }(2 / 3) \text {, hypoplastic CC (1/3), white } \\
\text { matter dysgenesis ( } 1 / 3)\end{array}$ & 3 & {$[86,99]$} \\
\hline PPP2R5C & & & 1 & \\
\hline p.T157del & $\mathrm{n} / \mathrm{a}$ & $\begin{array}{l}\text { Overgrowth, severe ID, hypotonia, seizures, conductive } \\
\text { hearing loss }\end{array}$ & 1 & [85] \\
\hline PPP2R5B & & & 1 & \\
\hline p.S161L & $\mathrm{n} / \mathrm{a}$ & Very tall height, moderate ID & 1 & [85] \\
\hline
\end{tabular}

Table 3: Overview of PP2A A and C subunit encoding genes harbouring monoallelic, de novo mutations, causally related to the aetiology of (neuro)developmental disorders. RNA transcripts for PPP2R1A: NM_014225.6 and PPP2CA: NM_002715.2. ADHD: attention deficit and hyperactivity disorder; ASD: autism spectrum disorder; CC: corpus callosum; DD developmental delay; ESES: electrical status epilepticus during sleep; ID: intellectual disability; HR: HEAT-repeat; n/a: not analysed; OCD: obsessive compulsive disorder; PDD-NOS: pervasive developmental disorder not otherwise specified; PVLM: periventricular leukomalacia; VM: ventriculomegaly.

\begin{tabular}{|c|c|c|c|c|}
\hline variant & Biochemical dysfunction & Clinical description & $\mathbf{n}^{\circ}$ cases & Ref. \\
\hline PPP2R1A & & & 37 & \\
\hline p.F141I & $\begin{array}{l}\text { HR4; normal } B 55, B 56 \delta \text { and } B^{\prime \prime \prime} \text { binding; loss of } \\
\text { binding to } B 56 \alpha, \beta, \gamma 1, \varepsilon \text { and } B^{\prime \prime} ; \text { decreased } C \\
\text { binding but normal activity }\end{array}$ & $\begin{array}{l}\text { Severe ID, macrocephaly, ADHD, hypotonia, } \\
\text { hypoplastic ears }\end{array}$ & 1 & [92] \\
\hline p.S152F & $\begin{array}{l}\text { HR4; no } B / C \text { subunit binding or activity } \\
\text { dysfunctions; less boutons upon expression in } \\
\text { primary rat neuron }\end{array}$ & No ID, normocephaly, ASD, normal muscle tone & 1 & [92] \\
\hline
\end{tabular}




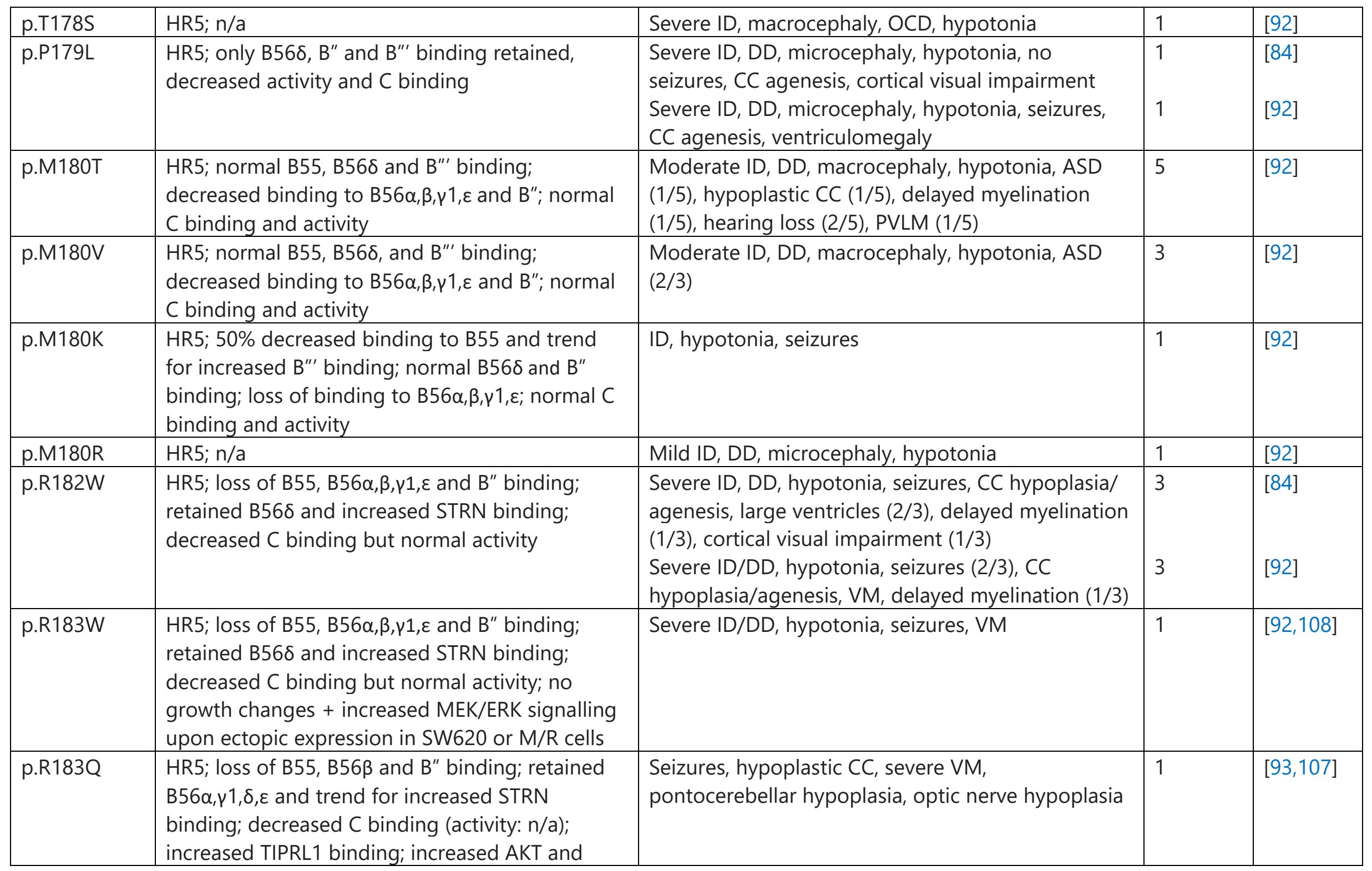




\begin{tabular}{|c|c|c|c|c|}
\hline & $\begin{array}{l}\text { mTOR/p70 S6 signalling + decreased ERK } \\
\text { signalling upon ectopic expression in HEC-1A } \\
\text { cells }\end{array}$ & & & \\
\hline p.S219L & $\begin{array}{l}\text { HR6; loss of B55 binding; decreased } B 56 \beta, \gamma 1, \varepsilon \\
\text { binding; retained binding to } B 56 \alpha, \delta \text { and } B^{\prime \prime} ; \\
\text { increased STRN binding; decreased C binding } \\
\text { but normal activity }\end{array}$ & $\begin{array}{l}\text { Moderate ID, DD, microcephaly (1/3), hypotonia, } \\
\text { ADHD (2/3), seizures (2/3), hypoplastic CC (2/3), VM } \\
(1 / 3) \\
\text { Seizures, CC agenesis, reduced brain parenchyma, } \\
\text { delayed myelination in the white matter, VM, } \\
\text { peripheral and central auditory impairment }\end{array}$ & 3 & [94] \\
\hline p.R258S & $\begin{array}{l}\text { HR7; loss of B55 and B" binding; retained B56 } \\
\text { binding; increased STRN3 binding; decreased } \\
\text { activity and C binding }\end{array}$ & DD, microcephaly & 1 & [92] \\
\hline PPP2CA & & & 16 & \\
\hline p.G60V & Very poor expression: null allele? & Mild ID/DD & 1 & [95] \\
\hline p.D88G & $\begin{array}{l}\text { Inactive + no methylation; decreased binding to } \\
\text { all B-type subunits except B56 } \gamma \text { and } \delta \text { : dominant- } \\
\text { negative effect on PP2A-B56 } \gamma \text { and } \delta\end{array}$ & $\begin{array}{l}\text { Severe ID/DD, seizures, enlarged subarachnoid } \\
\text { spaces, stereotypic movements, hypotonia }\end{array}$ & 1 & [95] \\
\hline p.Q122H & $\begin{array}{l}50 \% \text { decreased activity; binding to all B-type } \\
\text { subunits retained or even increased }\left(B 56 \alpha / \varepsilon, B^{\prime \prime \prime}\right)\end{array}$ & $\begin{array}{l}\text { Moderate ID/DD, microcephaly, seizures, enlarged } \\
\text { subarachnoid spaces, hypotonia }\end{array}$ & 1 & [95] \\
\hline p.Q125* & No expression, null allele & $\begin{array}{l}\text { Mild ID/DD, reduced white matter, global atrophy } \\
\text { of pons and CC, hypotonia, hypermobility }\end{array}$ & 1 & [95] \\
\hline p.Y127C & Inactive + no methylation; retained binding to & Severe ID/DD, microcephaly, mild VM, & 1 & [95] \\
\hline
\end{tabular}




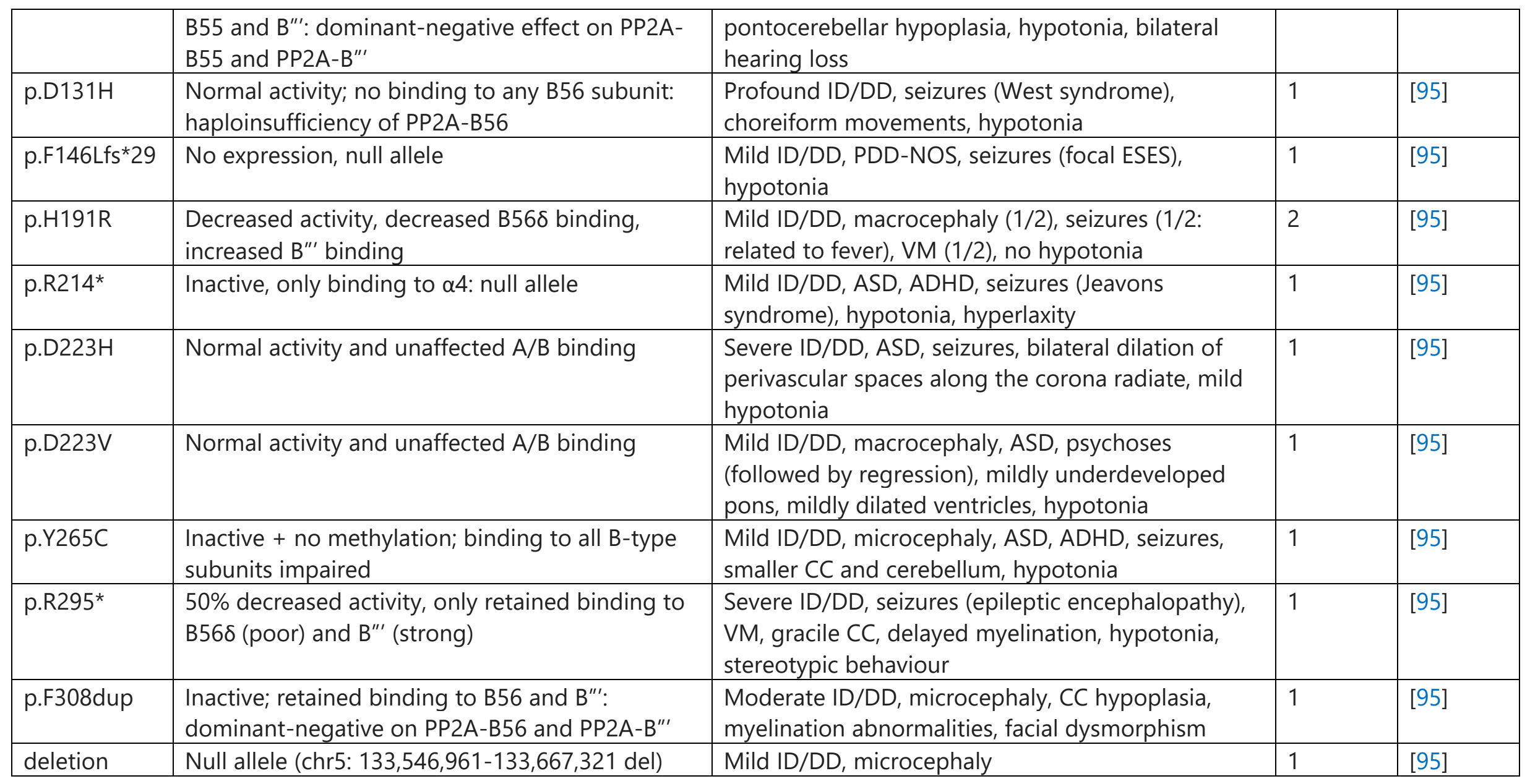

Table 4: Overview of PP2A regulator encoding genes harbouring mutations, causally related to the aetiology of (neuro)developmental disorders. RNA transcripts for SET: NM_001122821.1; SETBP1: NM_015559.2; BOD1: NM_138369.2; CIP2A: NM_020890.3. ADD: attention deficit disorder; CC: corpus callosum; DD: developmental delay; ID: intellectual disability; n/a: not analysed 


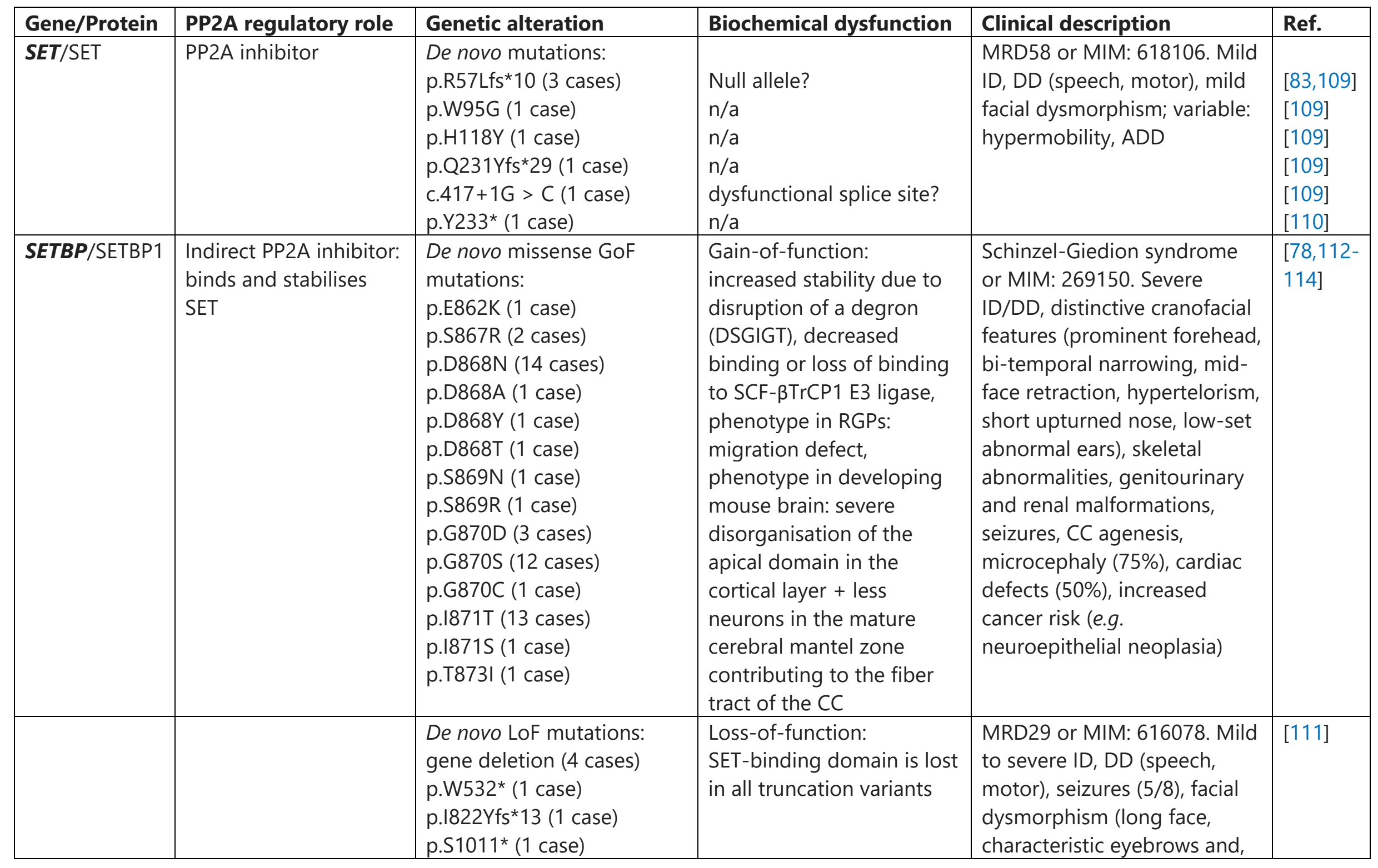




\begin{tabular}{|c|c|c|c|c|c|}
\hline & & $\begin{array}{l}\text {-Inheritance unknown: } \\
\text { p.G15Rfs*47 ( } 1 \text { case }) \\
\text { p.R143Vfs*64 ( } 1 \text { case }) \\
\text { p.L411Gf**6 }(1 \text { case }) \\
\text { p.K592* }(1 \text { case }) \\
\text { p.R625* } 1 \text { case }) \\
\text { p.R626* } 1 \text { case })\end{array}$ & & $\begin{array}{l}\text { less frequently, low-set ears } \\
\text { and café-au-lait spots), } \\
\text { hyperactivity, social and } \\
\text { behavioural difficulties }\end{array}$ & \\
\hline $\begin{array}{l}\text { BOD1/Bod1 } \\
\text { (MIM: 616745) }\end{array}$ & PP2A-B56 inhibitor & $\begin{array}{l}\text { Homozygous nonsense } \\
\text { variants: } \\
\text { p.R112* ( } 4 \text { cases in a large } \\
\text { consanguineous family) } \\
\text { p.R151* ( } 1 \text { case in a } \\
\text { consanguineous family) }\end{array}$ & $\begin{array}{l}\text { Loss-of-function: } \\
\text { nonsense mediated mRNA } \\
\text { decay, no protein } \\
\text { expression }\end{array}$ & $\begin{array}{l}\text { Mild to moderate ID } \\
\text { Moderate ID, DD, mild } \\
\text { dysmorphic features, high- } \\
\text { frequency hearing } \\
\text { impairment, endocrine } \\
\text { dysfunction (hypogonadism, } \\
\text { short stature) }\end{array}$ & $\begin{array}{l}{[79]} \\
{[116]}\end{array}$ \\
\hline
\end{tabular}




\section{References}

[1] Janssens, V. (2020) Serine/Threonine protein phosphatases. Reference Module in Life Sciences https://doi.org/10.1016/B978-0-12-819460-7.00084-0

[2] Reynhout, S. and Janssens, V. (2019) Physiologic functions of PP2A: Lessons from genetically modified mice. Biochim. Biophys. Acta Mol. Cell Res. 1866, 31-50 https://doi.org/10.1016/j.bbamcr.2018.07.010

[3] Sontag, J.M. and Sontag, E. (2014) Protein phosphatase 2A dysfunction in Alzheimer's disease. Front. Mol. Neurosci. 7, 16 https://doi.org/10.3389/fnmol.2014.00016

[4] Taymans, J.M. and Baekelandt, V. (2014) Phosphatases of alpha-synuclein, LRRK2, and tau: important players in the phosphorylation-dependent pathology of Parkinsonism. Front. Genet. 5, 382 https://doi.org/10.3389/fgene.2014.00382

[5] Park, H.J., Lee, K.W., Park, E.S., Oh, S., Yan, R., Zhang, J. et al. (2016) Dysregulation of protein phosphatase 2A in parkinson disease and dementia with lewy bodies. Ann. Clin. Transl. Neurol. 3, 769-780 https://doi.org/10.1002/acn3.337

[6] Janssens, V. and Goris, J. (2001) Protein phosphatase 2A: a highly regulated family of serine/threonine phosphatases implicated in cell growth and signaling. Biochem. J. 353, 417-439 https://doi.org/10.1042/0264-6021:3530417

[7] Kremmer, E., Ohst, K., Kiefer, J., Brewis, N. and Walter, G. (1997) Separation of PP2A core enzyme and holoenzyme with monoclonal antibodies against the regulatory $A$ subunit: abundant expression of both forms in cells. Mol. Cell. Biol. 17, 1692-1701 https://doi.org/10.1128/mcb.17.3.1692

[8] Waelkens, E., Agostinis, P., Goris, J. and Merlevede, W. (1987) The polycationstimulated protein phosphatases: regulation and specificity. Adv Enzyme Regul. 26, 241-270 https://doi.org/10.1016/0065-2571(87)90017-3

[9] Zhu, D., Tate, R.I., Ruediger, R., Meigs, T.E. and Denker, B.M. (2007) Domains necessary for Galpha12 binding and stimulation of protein phosphatase-2A (PP2A): Is Galpha12 a novel regulatory subunit of PP2A? Mol. Pharmacol. 71, 1268-1276 https://doi.org/10.1124/mol.106.033555 
[10] Zheng, H., Qi, Y., Hu, S., Cao, X., Xu, C., Yin, Z. et al. (2020) Identification of IntegratorPP2A complex (INTAC), an RNA polymerase II phosphatase. Science 370, eabb5872 https://doi.org/10.1126/science.abb5872

[11] Huang, K.L., Jee, D., Stein, C.B., Elrod, N.D., Henriques, T., Mascibroda, L.G. et al. (2020) Integrator recruits Protein Phosphatase 2A to prevent pause release and facilitate transcription termination. Mol. Cell 80, 345-358 https://doi.org/10.1016/j.molcel.2020.08.016

[12] Slupe, A.M., Merrill, R.A. and Strack, S. (2011) Determinants for substrate specificity of Protein Phosphatase 2A. Enzyme Res. 2011, 398751 https://doi.org/10.4061/2011/398751

[13] Lambrecht, C., Haesen, D., Sents, W., Ivanova, E. and Janssens, V. (2013) Structure, regulation, and pharmacological modulation of PP2A phosphatases. Methods Mol. Biol. 1053, 283-305 https://doi.org/10.1007/978-1-62703-562-0 17

[14] Sents, W., Ivanova, E., Lambrecht, C., Haesen, D. and Janssens, V. (2013) The biogenesis of active protein phosphatase 2A holoenzymes: a tightly regulated process creating phosphatase specificity. FEBS J. 280, 644-661 https://doi.org/10.1111/j.1742$\underline{4658.2012 .08579 . x}$

[15] Kong, M., Ditsworth, D., Lindsten, T. and Thompson, C.B. (2009) Alpha4 is an essential regulator of PP2A phosphatase activity. Mol. Cell 36, 51-60 https://doi.org/10.1016/j.molcel.2009.09.025

[16] Haesen, D., Sents, W., Ivanova, E., Lambrecht, C. and Janssens, V. (2012) Cellular inhibitors of protein phosphatase PP2A in cancer. Biomed. Res. 23,197-211

[17] Fan, L., Liu, M.H., Guo, M., Hu, C.X., Yan, Z.W., Chen, J. et al. (2016) FAM122A, a new endogenous inhibitor of protein phosphatase 2A. Oncotarget 7, 63887-63900 https://doi.org/10.18632/oncotarget.11698

[18] Kauko, O. and Westermarck, J. (2018) Non-genomic mechanisms of protein phosphatase 2A (PP2A) regulation in cancer. Int. J. Biochem. Cell. Biol. 96, 157-164 https://doi.org/10.1016/j.biocel.2018.01.005

[19] Dun, M.D., Mannan, A., Rigby, C.J., Butler, S., Toop, H.D., Beck, D. et al. (2020) Shwachman-Bodian-Diamond syndrome (SBDS) protein is a direct inhibitor of protein 
phosphatase 2A (PP2A) activity and overexpressed in acute myeloid leukaemia.

Leukemia 34, 3393-3397 https://doi.org/10.1038/s41375-020-0814-0

[20] Mäkelä ,E., Pavic, K., Varila, T., Salmenniemi, U., Löyttyniemi, E., Nagelli, S.G. et al. (2021) Discovery of a Novel CIP2A Variant (NOCIVA) with clinical relevance in predicting TKI resistance in myeloid leukemias. Clin. Cancer Res. in the press. https://doi.org/10.1158/1078-0432.CCR-20-3679

[21] Ewing, R.M, Chu, P., Elisma, F., Li, H., Taylor, P., Climie, S. et al. (2007) Large-scale mapping of human protein-protein interactions by mass spectrometry. Mol. Syst. Biol. 3, 89 https://doi.org/10.1038/msb4100134

[22] Chen, G.I., Tisayakorn, S., Jorgensen, C., D'Ambrosio, L.M., Goudreault, M. and Gingras, A.C. (2008) PP4R4/KIAA1622 forms a novel stable cytosolic complex with phosphoprotein phosphatase 4. J. Biol. Chem. 283, 29273-29284 https://doi.org/10.1074/jbc.M803443200

[23] Glatter, T., Wepf, A., Aebersold, R. and Gstaiger, M. (2009) An integrated workflow for charting the human interaction proteome: insights into the PP2A system. Mol. Syst.

Biol. 5, 237 https://doi.org/10.1038/msb.2008.75

[24] Wepf, A., Glatter, T., Schmidt, A., Aebersold, R. and Gstaiger, M. (2009) Quantitative interaction proteomics using mass spectrometry. Nat. Methods 6, 203-205 https://doi.org/10.1038/nmeth.1302

[25] Kono, Y., Maeda, K., Kuwahara, K., Yamamoto, H., Miyamoto, E., Yonezawa, K. et al. (2002) MCM3-binding GANP DNA-primase is associated with a novel phosphatase component G5PR. Genes Cells 7, 821-834 https://doi.org/10.1046/j.1365$\underline{2443.2002 .00562 . x}$

[26] Lubert, E.J., Hong, Y. and Sarge, K.D. (2001) Interaction between protein phosphatase 5 and the A subunit of protein phosphatase 2A: evidence for a heterotrimeric form of protein phosphatase 5. J. Biol. Chem. 276, 38582-38587 https://doi.org/10.1074/jbc.M106906200

[27] Kumar, P., Tathe, P., Chaudhary, N. and Maddika, S. (2019) PPM1G forms a PPP-type phosphatase holoenzyme with B56delta that maintains adherens junction integrity. EMBO Rep. 20, e46965 https://doi.org/10.15252/embr.201846965 
[28] Hertz, E.P.T., Kruse, T., Davey, N.E., López-Méndez, B., Sigurðsson, J.O., Montoya, G. et al. (2016) A conserved motif provides binding specificity to the PP2A-B56 phosphatase. Mol. Cell 63, 686-695 https://doi.org/10.1016/j.molcel.2016.06.024

[29] Wang, X., Bajaj, R., Bollen, M., Peti, W. and Page, R. (2016) Expanding the PP2A interactome by defining a B56-specific SLiM. Structure 24, 2174-2181 https://doi.org/10.1016/j.str.2016.09.010

[30] Maertens, G.N. (2016) B'-protein phosphatase 2A is a functional binding partner of delta-retroviral integrase. Nucl. Acids Res. 44, 364-376 https://doi.org/10.1093/nar/gkv1347

[31] Wang, J., Wang, Z., Yu, T., Yang, H., Virshup, D.M., Kops, G.J. et al. (2016) Crystal structure of a PP2A B56-BubR1 complex and its implications for PP2A substrate recruitment and localization. Protein Cell 7, 516-526 https://doi.org/10.1007/s13238$\underline{016-0283-4}$

[32] Wu, C.G., Chen, H., Guo, F., Yadav, V.K., Mcilwain, S.J., Rowse, M. et al. (2017) PP2A-B' holoenzyme substrate recognition, regulation and role in cytokinesis. Cell Discov. 3, 17027 https://doi.org/10.1038/celldisc.2017.27

[33] Kruse, T., Biedenkopf, N., Hertz, E.P.T., Dietzel, E., Stalmann, G., López-Méndez, B. et al. (2018) The Ebola Virus nucleoprotein recruits the host PP2A-B56 phosphatase to activate transcriptional support activity of VP30. Mol. Cell 69, 136-145 https://doi.org/10.1016/j.molcel.2017.11.034

[34] Cundell, M.J., Hutter, L.H., Nunes Bastos, R., Poser, E., Holder, J., Mohammed, S. et al. (2016) A PP2A-B55 recognition signal controls substrate dephosphorylation kinetics during mitotic exit. J. Cell Biol. 214, 539-554 https://doi.og/10.1083/jcb.201606033

[35] Wang, X., Garvanska, D.H., Nasa, I., Ueki, Y., Zhang, G., Kettenbach, A.N. et al. (2020) A dynamic charge-charge interaction modulates PP2A:B56 substrate recruitment. Elife $\mathbf{9}$, e55966 https://doi.org/10.7554/eLife.55966

[36] Jong, C.J., Merrill, R.A., Wilkerson, E.M., Herring, L.E., Graves, L.M. and Strack, S. (2020) Reduction of protein phosphatase 2A (PP2A) complexity reveals cellular functions and dephosphorylation motifs of the PP2A/B'S holoenzyme. J. Biol. Chem. 295, 5654-5668 https://doi.org/10.1074/jbc.RA119.011270 
[37] Kruse, T., Gnosa. S.P., Nasa, I., Garvanska, D.H., Hein, J.B., Nguyen, H. et al (2020) Mechanisms of site-specific dephosphorylation and kinase opposition imposed by PP2A regulatory subunits. EMBO J. 39, e103695 https://doi.org/10.15252/embj.2019103695

[38] Xu, Z., Cetin, B., Anger, M., Cho, U.S., Helmhart, W., Nasmyth, K. et al. (2009) Structure and function of the PP2A-shugoshin interaction. Mol. Cell 35, 426-441 https//doi.org/10.1016/j.molcel.2009.06.031

[39] Vallardi, G., Allan, L.A., Crozier, L. and Saurin, A.T. (2019) Division of labour between PP2A-B56 isoforms at the centromere and kinetochore. Elife 8, e42619 https://doi.org/10.7554/eLife.42619

[40] Agostinis, P., Derua, R., Sarno, S., Goris, J. and Merlevede, W. (1992) Specificity of the polycation-stimulated (type-2A) and ATP,Mg-dependent (type-1) protein phosphatases toward substrates phosphorylated by P34cdc2 kinase. Eur. J. Biochem. 205, 241-248 https://doi.org/10.1111/j.1432-1033.1992.tb16774.x

[41] Schott, K., Fuchs, N.V., Derua, R., Mahboubi, B., Schnellbächer, E., Seifried, J. et al. (2018) Dephosphorylation of the HIV-1 restriction factor SAMHD1 is mediated by PP2A-B55 $\alpha$ holoenzymes during mitotic exit. Nat. Commun. 9, 2227 https://doi.org/10.1038/s41467-018-04671-1

[42] Stamatoyannopoulos, J.A., Snyder, M., Hardison, R., Ren, B., Gingeras, T., Gilbert, D.M. et al. (2012) An encyclopedia of mouse DNA elements (Mouse ENCODE). Genome Biol. 13, 418 https://doi.org/10.1186/gb-2012-13-8-418

[43] Khew-Goodall, Y., Mayer, R.E., Maurer, F., Stone, S.R. and Hemmings, B.A. (1991) Structure and transcriptional regulation of protein phosphatase $2 \mathrm{~A}$ catalytic subunit genes. Biochemistry 30, 89-97 https://doi.org/10.1021/bi00215a014

[44] Hemmings, B.A., Adams-Pearson, C., Maurer, F., Müller, P., Goris, J., Merlevede, W. et al. (1990) alpha- and beta-forms of the $65-k D a$ subunit of protein phosphatase 2A have a similar 39 amino acid repeating structure. Biochemistry 29, 3166-3173 https://doi.org/10.1021/bi00465a002 
[45] Strack, S., Zaucha, J.A., Ebner, F.F., Colbran, R.J. and Wadzinski, B.E. (1998) Brain protein phosphatase 2A: developmental regulation and distinct cellular and subcellular localization by B subunits. J. Comp. Neurol. 392, 515-527

[46] Strack, S. (2002) Overexpression of the protein phosphatase 2A regulatory subunit Bgamma promotes neuronal differentiation by activating the MAP kinase (MAPK) cascade. J. Biol. Chem. 277, 41525-41532 https://doi.org/10.1074/jbc.M203767200

[47] Schmidt, K., Kins, S., Schild, A., Nitsch, R.M., Hemmings, B.A. and Gotz, J. (2002) Diversity, developmental regulation and distribution of murine PR55/B subunits of protein phosphatase 2A. Eur. J. Neurosci. 16, 2039-2048 https://doi.org/10.1046/j.1460-9568.2002.02274.x

[48] Martens, E., Stevens, I., Janssens, V., Vermeesch, J., Götz, J., Goris, J. et al. (2004) Genomic organisation, chromosomal localisation tissue distribution and developmental regulation of the PR61/B' regulatory subunits of protein phosphatase 2A in mice. J. Mol. Biol. 336, 971-986 https//doi.org/10.1016/j.jmb.2003.12.047

[49] Saraf, A., Virshup, D.M. and Strack, S. (2007) Differential expression of the B'beta regulatory subunit of protein phosphatase $2 \mathrm{~A}$ modulates tyrosine hydroxylase phosphorylation and catecholamine synthesis. J. Biol. Chem. 282, 573-580 https://doi.org/10.1074/jbc.M607407200

[50] van Lookeren Campagne, M., Okamoto, K., Prives, C. and Gill, R. (1999) Developmental expression and co-localization of cyclin G1 and the B' subunits of protein phosphatase 2a in neurons. Brain Res. Mol. Brain Res. 64, 1-10 https://doi.org/10.1016/s0169-328x(98)00283-6

[51] Louis, J.V., Martens, E., Borghgraef, P., Lambrecht, C., Sents, W., Longin, S. et al. (2011) Mice lacking phosphatase PP2A subunit PR61/B'delta (Ppp2r5d) develop spatially restricted tauopathy by deregulation of CDK5 and GSK3beta. Proc. Natl. Acad. Sci. U.S.A. 108, 6957-6962 https://doi.org/10.1073/pnas.1018777108

[52] Castets, F., Rakitina, T., Gaillard, S., Moqrich, A., Mattei, M.G. and Monneron, A. (2000) Zinedin, SG2NA, and striatin are calmodulin-binding, WD repeat proteins principally expressed in the brain. J. Biol. Chem. 275, 19970-19977 https://doi.org/10.1074/jbc.M909782199 
[53] Gaillard, S., Bailly, Y., Benoist, M., Rakitina, T., Kessler, J.P., Fronzaroli-Molinières, L. et al. (2006) Targeting of proteins of the striatin family to dendritic spines: role of the coiled-coil domain. Traffic 7, 74-84 https://doi.org/10.1111/j.1600-0854.2005.00363.x

[54] Benoist, M., Baude, A., Tasmadjian, A., Dargent, B., Kessler, J.P. and Castets, F. (2008) Distribution of zinedin in the rat brain. J. Neurochem. 106, 969-977 https://doi.org/10.1111/j.1471-4159.2008.05448.x

[55] Goldbaum, O. and Richter-Landsberg, C. (2002) Activation of PP2A-like phosphatase and modulation of tau phosphorylation accompany stress-induced apoptosis in cultured oligodendrocytes. Glia 40, 271-282 https://doi.org/10.1002/glia.10119

[56] Saitoh, Y., Yamamoto, H., Ushio, Y. and Miyamoto, E. (1989) Characterization of polyclonal antibodies to brain protein phosphatase 2A and immunohistochemical localization of the enzyme in rat brain. Brain Res. 489, 291-301 https://doi.org/10.1016/0006-8993(89)90862-7

[57] Saito, T., Shima, H., Osawa, Y., Nagao, M., Hemmings, B.A., Kishimoto, T. et al. (1995) Neurofilament-associated protein phosphatase 2A: its possible role in preserving neurofilaments in filamentous states. Biochemistry 34, 7376-7384 https://doi.org/10.1021/bi00022a010

[58] Sontag, E., Nunbhakdi-Craig, V., Lee, G., Bloom, G.S. and Mumby, M.C. (1996) Regulation of the phosphorylation state and microtubule-binding activity of Tau by protein phosphatase 2A. Neuron 17, 1201-1207 https://doi.org/10.1016/s0896$\underline{6273(00) 80250-0}$

[59] Liu, B., Sun, L.H., Huang, Y.F., Guo, L.J. and Luo, L.S. (2018) Protein phosphatase 2ACalpha gene knock-out results in cortical atrophy through activating hippo cascade in neuronal progenitor cells. Int. J. Biochem. Cell. Biol. 95, 53-62 https://doi.org/10.1016/j.biocel.2017.12.015

[60] Jeong, B.C., Bae, S.J., Ni, L., Zhang, X., Bai, X.C. and Luo, X. (2021) Cryo-EM structure of the Hippo signaling integrator human STRIPAK. Nat. Struct. Mol. Biol. 28, 290-299 https://doi.org/10.1038/s41594-021-00564-y

[61] Gil-Ranedo, J., Gonzaga, E., Jaworek, K.J., Berger, C., Bossing, T. and Barros, C.S. (2019) STRIPAK members orchestrate Hippo and Insulin Receptor signaling to promote 
neural stem cell reactivation. Cell Rep. 27, 2921-2933.e5

https://doi.org/10.1016/j.celrep.2019.05.023

[62] Kerosuo, L., Fox, H., Perälä, N., Ahlqvist, K., Suomalainen, A., Westermarck, J. et al. (2010) CIP2A increases self-renewal and is linked to Myc in neural progenitor cells. Differentiation 80, 68-77 https://doi.org/10.1016/j.diff.2010.04.003

[63] Kerosuo, L., Neppala, P., Hsin, J., Mohlin, S., Vieceli, F.M., Török, Z. et al. (2018) Enhanced expression of MycN/CIP2A drives neural crest toward a neural stem cell-like fate: Implications for priming of neuroblastoma. Proc. Natl. Acad. Sci. U. S. A. 115, E7351-E7360 https://doi.org/10.1073/pnas.1800039115

[64] Huang, C., Liu, T., Wang, Q., Hou, W., Zhou, C., Song, Z. et al. (2020) Loss of PP2A disrupts the retention of radial glial progenitors in the telencephalic niche to impair the generation for late-born neurons during cortical development. Cereb. Cortex 30, 4183-4196 https://doi.org/10.1093/cercor/bhaa042

[65] Wang, J., Xie, R., Kou, X., Liu, Y., Qi, C., Liu, R. et al. (2019) A protein phosphatase 2A deficit in the hippocampal CA1 area impairs memory extinction. Mol. Brain 12, 51 https://doi.org/10.1186/s13041-019-0469-9

[66] Wang, X., Blanchard, J., Kohlbrenner, E., Clement, N., Linden, R.M., Radu, A. et al. (2010) The carboxy-terminal fragment of inhibitor-2 of protein phosphatase-2A induces Alzheimer disease pathology and cognitive impairment. FASEB J. 24, 44204432 https://doi.org/10.1096/fj.10-158477

[67] Shentu, Y.P., Huo, Y., Feng, X.L., Gilbert, J., Zhang, Q., Liuyang, Z.Y. et al. (2018) CIP2A causes Tau/APP phosphorylation, synaptopathy, and memory deficits in Alzheimer's Disease. Cell Rep. 24, 713-723 https://doi.org/10.1016/j.celrep.2018.06.009

[68] Shentu, Y.P., Hu, W.T., Zhang, Q., Huo, Y., Liang, J.W., Liuyang, Z.Y. et al. (2019) CIP2Apromoted astrogliosis induces AD-like synaptic degeneration and cognitive deficits. Neurobiol. Aging 75, 198-208 https://doi.org/10.1016/j.neurobiolaging.2018.11.023 [69] Panicker, N., Coutman, M., Lawlor-O'Neill, C., Kahl, R.G.S., Roselli, S. and Verrills, N.M. (2020) Ppp2r2a knockout mice reveal that Protein Phosphatase 2A regulatory subunit, PP2A-B55 $\alpha$, is an essential regulator of neuronal and epidermal embryonic development. Front. Cell. Dev. Biol. 8, 358 https://doi.org/10.3389/fcell.2020.00358 
[70] Flippo, K.H., Lin, Z., Dickey, A.S., Zhou, X., Dhanesha, N.A. et al. (2020) Deletion of a neuronal Drp1 activator protects against cerebral ischemia. J. Neurosci. 40, 3119-3129 https://doi.org/10.1523/JNEUROSCI.1926-19.2020

[71] Janghorban, M., Langer, E.M., Wang, X., Zachman, D., Daniel, C.J., Hooper, J. et al. (2017) The tumor suppressor phosphatase PP2A-B56alpha regulates stemness and promotes the initiation of malignancies in a novel murine model. PLoS One 12, e0188910 https://doi.org/10.1371/journal.pone.0188910

[72] Little, S.C., Curran, J., Makara, M.A., Kline, C.F., Ho, H.T., Xu, Z. et al. (2015) Protein phosphatase $2 \mathrm{~A}$ regulatory subunit B56 $\alpha$ limits phosphatase activity in the heart. Sci. Signal. 8, ra72 https://doi.org/10.1126/scisignal.aaa5876

[73] Varadkar, P., Despres, D., Kraman, M., Lozier, J., Phadke, A., Nagaraju, K. et al. (2014) The protein phosphatase $2 \mathrm{~A} B 56 \mathrm{y}$ regulatory subunit is required for heart development. Dev. Dyn. 243, 778-790 https://doi.org/10.1002/dvdy.24111

[74] Kapfhamer, D., Berger, K.H., Hopf, F.W., Seif, T., Kharazia, V., Bonci, A. et al. (2010) Protein Phosphatase $2 \mathrm{a}$ and glycogen synthase kinase 3 signaling modulate prepulse inhibition of the acoustic startle response by altering cortical M-Type potassium channel activity. J. Neurosci. 30, 8830-8840 https://doi.org/10.1523/JNEUROSCI.1292$\underline{10.2010}$

[75] Nadar-Ponniah, P.T., Taiber, S., Caspi, M., Koffler-Brill, T., Dror, A.A., Siman-Tov, R. et al. (2020) Striatin is required for hearing and affects inner hair cells and ribbon synapses. Front. Cell Dev. Biol. 8, 615 https://doi.org/10.3389/fcell.2020.00615

[76] Yamashita, T., Inui, S., Maeda, K., Hua, D.R., Takagi, K., Fukunaga, K. et al. (2006) Regulation of CaMKII by alpha4/PP2Ac contributes to learning and memory. Brain Res. 1082, 1-10 https://doi.org/10.1016/j.brainres.2006.01.101

[77] Trakhtenberg, E.F., Wang, Y., Morkin, M.I., Fernandez, S.G., Mlacker, G.M., Shechter, J.M. et al. (2014) Regulating Set- $\beta$ 's subcellular localization toggles its function between inhibiting and promoting axon growth and regeneration. J. Neurosci. 34, 7361-7374 https://doi.org/10.1523/JNEUROSCI.3658-13.2014 
[78] Piazza, R., Magistroni, V., Redaelli, S., Mauri, M., Massimino, L., Sessa, A. et al. (2018) SETBP1 induces transcription of a network of development genes by acting as an epigenetic hub. Nat. Commun. 9, 2192 https://doi.org/10.1038/s41467-018-04462-8

[79] Esmaeeli-Nieh, S., Fenckova, M., Porter, I.M., Motazacker, M.M., Nijhof, B., CastellsNobau, A. et al. (2016) BOD1 is required for cognitive function in humans and Drosophila. PLoS Genet. 12, e1006022 https://doi.org/10.1371/journal.pgen.1006022

[80] Ventelä, S., Côme, C., Mäkelä, J.A., Hobbs, R.M., Mannermaa, L., Kallajoki, M. et al. (2012) CIP2A promotes proliferation of spermatogonial progenitor cells and spermatogenesis in mice. PLoS One 7, e33209 https://doi.org/10.1371/journal.pone.0033209

[81] Leslie, S.N. and Nairn, A.C. (2019) cAMP regulation of protein phosphatases PP1 and PP2A in brain. Biochim. Biophys. Acta Mol. Cell Res. 1866, 64-73

https://doi.org/10.1016/j.bbamcr.2018.09.006

[82] Andrade, E.C., Musante, V., Horiuchi, A., Matsuzaki, H., Brody, A.H., Wu, T. et al. (2017) ARPP-16 is a striatal-enriched inhibitor of Protein Phosphatase 2A regulated by microtubule-associated serine/threonine kinase 3 (Mast 3 Kinase). J. Neurosci. 37, 2709-2722 https://doi.org/10.1523/JNEUROSCl.4559-15.2017

[83] Deciphering Developmental Disorders Study, Fitzgerald, T.W, Gerety, S.S., Jones, W.D., van Kogelenberg, M., King, D.A. et al. (2015) Large-scale discovery of novel genetic causes of developmental disorders. Nature 519, 223-228 https://doi.org/10.1038/nature14135

[84] Houge, G., Haesen, D., Vissers, L.E., Mehta, S., Parker, M.J., Wright, M. et al. (2015) B568-related protein phosphatase 2A dysfunction identified in patients with intellectual disability. J. Clin. Invest. 125, 3051-3062 https://doi.org/10.1172/JCI79860

[85] Loveday, C., Tatton-Brown, K., Clarke, M., Westwood, I., Renwick, A., Ramsay, E. et al. (2015) Mutations in the PP2A regulatory subunit B family genes PPP $2 R 5 B, P P P 2 R 5 C$ and PPP2R5D cause human overgrowth. Hum. Mol. Genet. 24, 4775-4779 https://doi.org/10.1093/hmg/ddv182

[86] Shang, L., Henderson, L.B., Cho, M.T., Petrey, D.S., Fong, C.T., Haude, K.M. et al. (2016) De novo missense variants in PPP2R5D are associated with intellectual disability, 
macrocephaly, hypotonia, and autism. Neurogenetics 17, 43-49

https://doi.org/10.1007/s10048-015-0466-9

[87] Yeung, K.S., Tso, W.W.Y., Ip, J.J.K., Mak, C.C.Y., Leung, G.K.C., Tsang, M.H.Y. et al. (2017) Identification of mutations in the PI3K-AKT-mTOR signalling pathway in patients with macrocephaly and developmental delay and/or autism. Mol. Autism 8, 66 https://doi.org/10.1186/s13229-017-0182-4

[88] Yan, L., Shen, R., Cao, Z., Han, C., Zhang, Y., Liu, Y. et al. (2021) A novel missense variant in the gene PPP2R5D causes a rare neurodevelopmental disorder with increased phenotype. Biomed. Res. Int. 2021, 6661860 https://doi.org/10.1155/2021/6661860

[89] Kim, C.Y., Wirth, T., Hubsch, C., Németh, A.H., Okur, V., Anheim, M. et al. (2020) Earlyonset parkinsonism is a manifestation of the PPP2R5D p.E200K mutation. Ann. Neurol. 88, 1028-1033 https://doi.org/10.1002/ana.25863

[90] Walker, I.M., Riboldi, G.M., Drummond, P., Saade-Lemus, S., Martin-Saavedra, J.S., Frucht, S. et al. (2021) PPP2R5D genetic mutations and early-onset parkinsonism. Ann. Neurol. 89, 194-195 https://doi.org/10.1002/ana.25943

[91] Hetzelt, K.L.M.L., Kerling, F., Kraus, C., Rauch, C., Thiel, C.T., Winterholler, M. et al. (2021) Early-onset parkinsonism in PPP2R5D-related neurodevelopmental disorder. Eur. J. Med. Genet. 64, 104123 https://doi.org/10.1016/j.ejmg.2020.104123

[92] Lenaerts, L., Reynhout, S., Verbinnen, I., Laumonnier, F., Toutain, A., Bonnet-Brilhault, F. et al. (2021) The broad phenotypic spectrum of PPP2R1A-related neurodevelopmental disorders correlates with the degree of biochemical dysfunction. Genet. Med. 23, 352-362 https://doi.org/10.1038/s41436-020-00981-2

[93] Wallace, A., Caruso, P. and Karaa, A. (2019) A newborn with severe ventriculomegaly: expanding the PPP2R1A gene mutation phenotype. J. Pediatr. Genet. 8, 240-243 https://doi.org/10.1055/s-0039-1692414

[94] Zhang, Y., Li, H., Wang, H., Jia, Z., Xi, H. and Mao, X. (2020) A de novo variant identified in the PPP2R1A gene in an infant induces neurodevelopmental abnormalities. Neurosci. Bull. 36, 179-182 https://doi.org/10.1007/s12264-019-00430$\underline{4}$ 
[95] Reynhout, S., Jansen, S., Haesen, D., Van Belle, S., de Munnik, S.A., Bongers, E.M.H.F. et al. (2019) De novo mutations affecting the catalytic C $\alpha$ subunit of PP2A (PPP2CA) cause syndromic intellectual disability resembling other PP2A-related neurodevelopmental disorders. Am. J. Hum. Genet. 104, 139-156 https://doi.org/10.1016/j.ajhg.2018.12.002

[96] Mirzaa, G., Foss, K., Nattakom, M. and Chung, W. (2019) PPP2R5D-retaled neurodevelopmental disorder. In: GeneReviews ${ }^{\circledR}$, Adam, M.P., Ardinger, H.H., Pagon, R.A., Wallace, S.E., Bean, L.J.H., Stephens, K. and Amemiya, A., editors. Seattle (WA): University of Washington: Seattle, WA, USA; 1993-2020

[97] Saraf, A., Oberg, E.A. and Strack, S. (2010) Molecular determinants for PP2A substrate specificity: charged residues mediate dephosphorylation of tyrosine hydroxylase by the PP2A/B' regulatory subunit. Biochemistry 49, 986-995 https://doi.org/10.1021/bi902160t

[98] Cho, U.S and Xu, W. (2007) Crystal structure of a protein phosphatase 2A heterotrimeric holoenzyme. Nature 445, 53-57 https://do.org/10.1038/nature05351 [99] Papke, C.M., Smolen, K.A., Swingle, M.R., Cressey, L., Heng, R.A., Toporsian, M. et al. (2021) A disorder-related variant (E420K) of a PP2A-regulatory subunit (PPP2R5D) causes constitutively active AKT-mTOR signaling and uncoordinated cell growth. J. Biol. Chem. 296, 100313 https://doi.org/10.1016/j.jbc.2021.100313

[100] Tadmouri, A., Kiyonaka, S., Barbado, M., Rousset, M., Fablet, K., Sawamura, S. et al. (2012) Cacnb4 directly couples electrical activity to gene expression, a process defective in juvenile epilepsy. EMBO J. 31, 3730-3744 https://doi.org/10.1038/emboj.2012.226

[101] Ahn, J.H., Kim, Y., Kim, H.S., Greengard, P. and Nairn, A.C. (2011) Protein kinase Cdependent dephosphorylation of tyrosine hydroxylase requires the B56 $\delta$ heterotrimeric form of protein phosphatase 2A. PLoS One 6, e26292 https://doi.org/10.1371/journal.pone.0026292

[102] Ahn, J.H., McAvoy, T., Rakhilin, S.V., Nishi, A., Greengard, P. and Nairn, A.C. (2007) Protein kinase A activates protein phosphatase 2A by phosphorylation of the B56delta 
subunit. Proc. Natl. Acad. Sci. U.S.A. 104, 2979-2984

https://doi.org/10.1073/pnas.0611532104

[103] Zhang, X., Gao, F., Wang, D., Li, C., Fu Y., He, W. et al. (2018) Tau Pathology in

Parkinson's Disease. Front. Neurol. 9, 809 https://doi.org/10.3389/fneur.2018.00809

[104] Lambrecht, C., Libbrecht, L., Sagaert, X., Pauwels, P., Hoorne, Y., Crowther, J. et al.

(2018) Loss of protein phosphatase 2A regulatory subunit B56 $\delta$ promotes

spontaneous tumorigenesis in vivo. Oncogene $37,544-552$

https://doi.org/10.1038/onc.2017.350

[105] Lambrecht, C., Bomfim Ferreira, G., Domènech Omella, J., Libbrecht, L., De Vos, R., Derua, R. et al. (2020) Differential proteomic analysis of hepatocellular carcinomas from Ppp2r5d knockout mice and normal (knockout) livers. Cancer Genomics

Proteomics 17, 669-685 https://doi.org/10.21873/cgp.20222

[106] Remmerie, M. and Janssens, V. (2019) PP2A: A promising biomarker and therapeutic target in endometrial cancer. Front. Oncol. 9, 462

https://doi.org/10.3389/fonc.2019.00462

[107] Haesen, D., Abbasi Asbagh, L., Derua, R., Hubert, A., Schrauwen, S., Hoorne, Y. et al. (2016) Recurrent PPP2R1A mutations in uterine cancer act through a dominantnegative mechanism to promote malignant cell growth. Cancer Res. 76, 5719-5731 https://doi.org/10.1158/0008-5472.CAN-15-3342

[108] O'Connor, C.M, Leonard, D., Wiredja, D., Avelar, R.A., Wang, Z., Schlatzer, D. et al. (2020) Inactivation of PP2A by a recurrent mutation drives resistance to MEK inhibitors.

Oncogene 39, 703-717 https://doi.org/10.1038/s41388-019-1012-2

[109] Stevens, S.J.C., van der Schoot, V., Leduc, M.S., Rinne, T., Lalani, S.R., Weiss, M.M. et al. (2018) De novo mutations in the SET nuclear proto-oncogene, encoding a component of the inhibitor of histone acetyltransferases (INHAT) complex in patients with nonsyndromic intellectual disability. Hum. Mutat. 39, 1014-1023 https://doi.org/10.1002/humu.23541

[110] Hamdan, F.F., Srour, M., Capo-Chichi, J.M., Daoud, H., Nassif, C., Patry, L. et al. (2014) De novo mutations in moderate or severe intellectual disability. PLoS Genet. 10, e1004772 https://doi.org/10.1371/journal.pgen.1004772 
[111] Coe, B.P., Witherspoon, K., Rosenfeld, J.A., van Bon, B.W., Vulto-van Silfhout, A.T., Bosco, P. et al. (2014) Refining analyses of copy number variation identifies specific genes associated with developmental delay. Nat. Genet. 46, 1063-1071 https://doi.org/10.1038/ng.3092

[112] Hoischen, A., van Bon, B.W., Gilissen, C., Arts, P., van Lier, B., Steehouwer, M. et al. (2010) De novo mutations of SETBP1 cause Schinzel-Giedion syndrome. Nat. Genet. 42, 483-485 https://doi.org/10.1038/ng.581

[113] Piazza, R., Valletta, S., Winkelmann, N., Redaelli, S., Spinelli, R., Pirola, A. et al. (2013) Recurrent SETBP1 mutations in atypical chronic myeloid leukemia. Nat. Genet. 45, 1824 https://doi.org/10.1038/ng.2495

[114] Acuna-Hidalgo, R., Deriziotis, P., Steehouwer, M., Gilissen, C., Graham, S.A., van Dam, S. et al. (2017) Overlapping SETBP1 gain-of-function mutations in Schinzel-Giedion syndrome and hematologic malignancies. PLoS Genet. 13, e1006683 https://doi.org/10.1371/journal.pgen.1006683

[115] Yang, C.A., Chou, I.C., Cho, D.Y., Lin, C.Y., Huang, H.Y., Ho, Y.C. et al. (2018) Whole exome sequencing in Dandy-Walker variant with intellectual disability reveals an activating CIP2A mutation as novel genetic cause. Neurogenetics 19, 157-163 https://doi.org/10.1007/s10048-018-0548-6

[116] Hamdan, N., Mehawej, C., Sebaaly, G., Jalkh, N., Corbani, S., Abou-Ghoch, J. et al. (2020) A homozygous stop gain mutation in BOD1 gene in a Lebanese patient with syndromic intellectual disability. Clin. Genet. 98, 288-292 https://doi.org/10.1111/cge.13799

[117] Clark, A.R. and Ohlmeyer, M. (2019) Protein phosphatase 2A as a therapeutic target in inflammation and neurodegeneration. Pharmacol. Ther. 201, 181-201 https://doi.org/10.1016/j.pharmthera.2019.05.016

[118] Morita, K., He, S., Nowak, R.P., Wang, J., Zimmerman, M.W., Fu, C. et al. (2020) Allosteric activators of Protein Phosphatase 2A display broad antitumor activity mediated by dephosphorylation of MYBL2. Cell 181, 702-715.e20 https://doi.org/10.1016/j.cell.2020.03.051 
[119] Leonard D, Huang W, Izadmehr S, O'Connor CM, Wiredja DD, Wang Z. et al. (2020) Selective PP2A enhancement through biased heterotrimer stabilization. Cell 181, 688701.e16 https://doi.org/10.1016/j.cell.2020.03.038

[120] Vervoort, S.J., Welsh, S.A., Devlin, J.R., Barbieri, E., Knight, D.A., Offley, S. et al. (2021) The PP2A-Integrator-CDK9 axis fine-tunes transcription and can be targeted therapeutically in cancer. Cell in the press. https://doi.org/10.1016/j.cell.2021.04.022 


\section{Author contributions}

All authors were involved in writing and reviewing the manuscript. IV, PV and VJ produced figures and tables.

\section{Declaration of Interests}

Authors declare no conflicts of interest associated with this manuscript.

\section{Acknowledgements}

Authors wish to acknowledge funding from the Jordan's Guardian Angels Foundation (to VJ), the Research Foundation-Flanders (to SR), and the 'Steunfonds Stichting MargueriteMarie Delacroix' (to PV).

\section{Abbreviations}

AD, Alzheimer's Disease; ADHD, attention deficit and hyperactivity disorder; ARPP-16/19, CAMP-Regulated Phospho-Protein of 16/19 kDa; ASD, autism spectrum disorder; BOD1, Biorientation Of chromosomes in cell Division 1; CACNB4, calcium channel voltagedependent beta 4 subunit; CA, cornu ammonis; CC, corpus callosum; CIP2A, Cancerous Inhibitor of PP2A; DARPP-32, Dopamine and CAMP-Regulated Phospho-Protein of 32 $\mathrm{kDa}$; DD, developmental delay; DG, dentate gyrus; Drp-1, dynamin-related protein 1; ESES, electrical status epilepticus during sleep; GoF, gain-of-function; GSK-3 $\beta$, glycogen synthase kinase-3ß; HR, HEAT-repeat; ID, intellectual disability; INTAC, Integrator-PP2A AC complex; KI, knockin; KO, knockout; LCMT1, leucine carboxyl methyl transferase 1; LoF, loss-of-function; LTD, long-term depression; LTP, long-term potentiation; NCS, neuronal stem cell; NDD, neurodevelopmental disorder; NGF, neuronal growth factor; NPC, neuronal progenitor cell; OCD, obsessive compulsive disorder; PD, Parkinson's Disease; PDD-NOS, pervasive developmental disorder not otherwise specified; PKA, CAMP-dependent protein kinase; PME-1, PP2A Methyl Esterase 1; PP2A, Protein Phosphatase 2A; PPI, pre-pulse inhibition; PTPA, PP Two A Activator; PVLM, periventricular leukomalacia; RGP, radial glial progenitor; SET, Suvar/Enhancer of zeste/Trithorax; SETBP1, SET Binding Protein 1; Sgo1, shugoshin; SLiM, short linear interaction motif; $\mathrm{TH}$, tyrosine hydroxylase; VM, ventriculomegaly. 
A PP2A Heterotrimers

$$
\begin{aligned}
& \left.\begin{array}{l}
P P P 2 R 1 A \\
P P P 2 R 1 B
\end{array}\right]-\quad \begin{array}{l}
P P P 2 R 2 A, B, C, D \\
\text { PR65/A }
\end{array}
\end{aligned}
$$

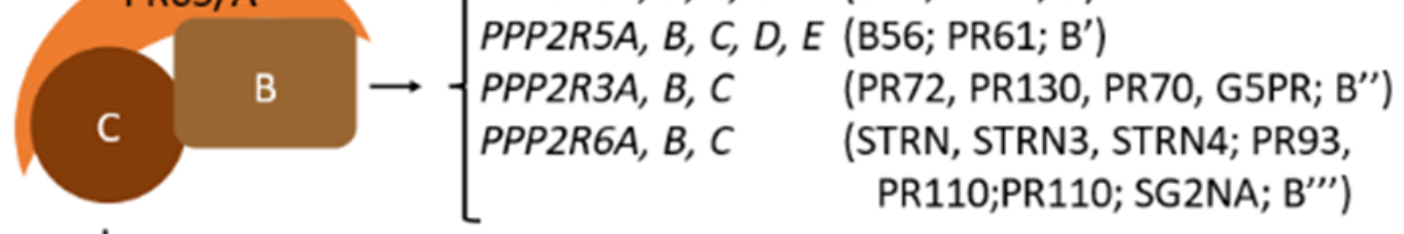

$$
\begin{aligned}
& \left\llcorner\left\{\begin{array}{l}
P P P 2 C A \\
P P P 2 C B
\end{array}\right.\right.
\end{aligned}
$$

\section{PP2A Core Dimers}

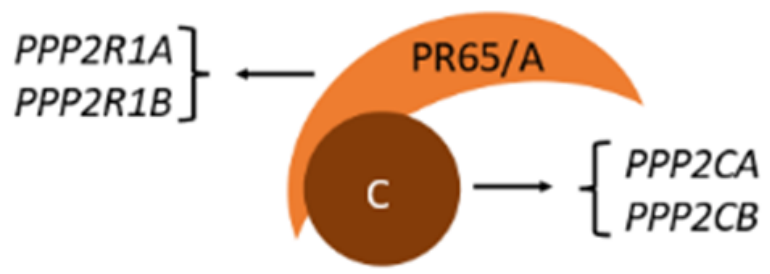

B Non-canonical complexes Intermediate, inactive complexes

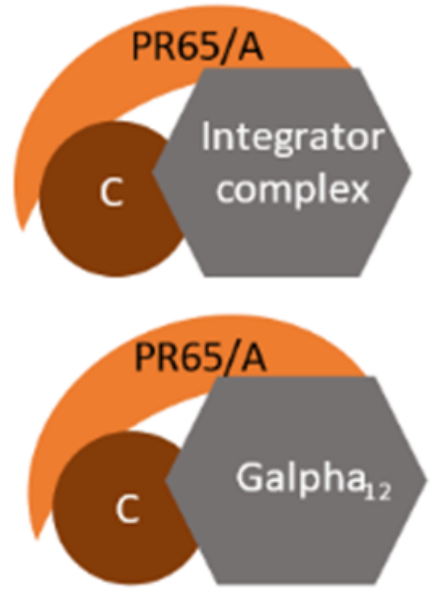

C Activators
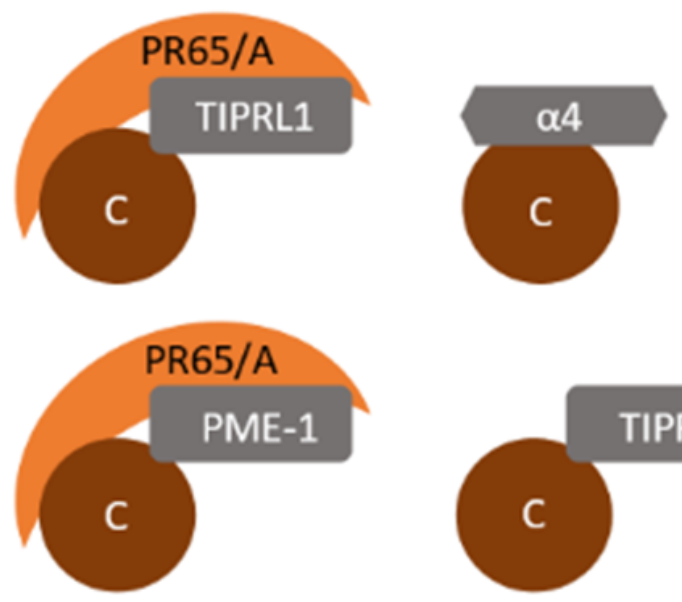

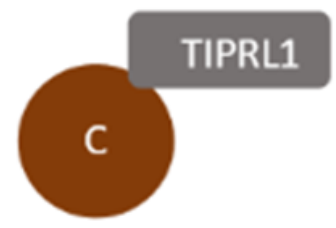

Inhibitors

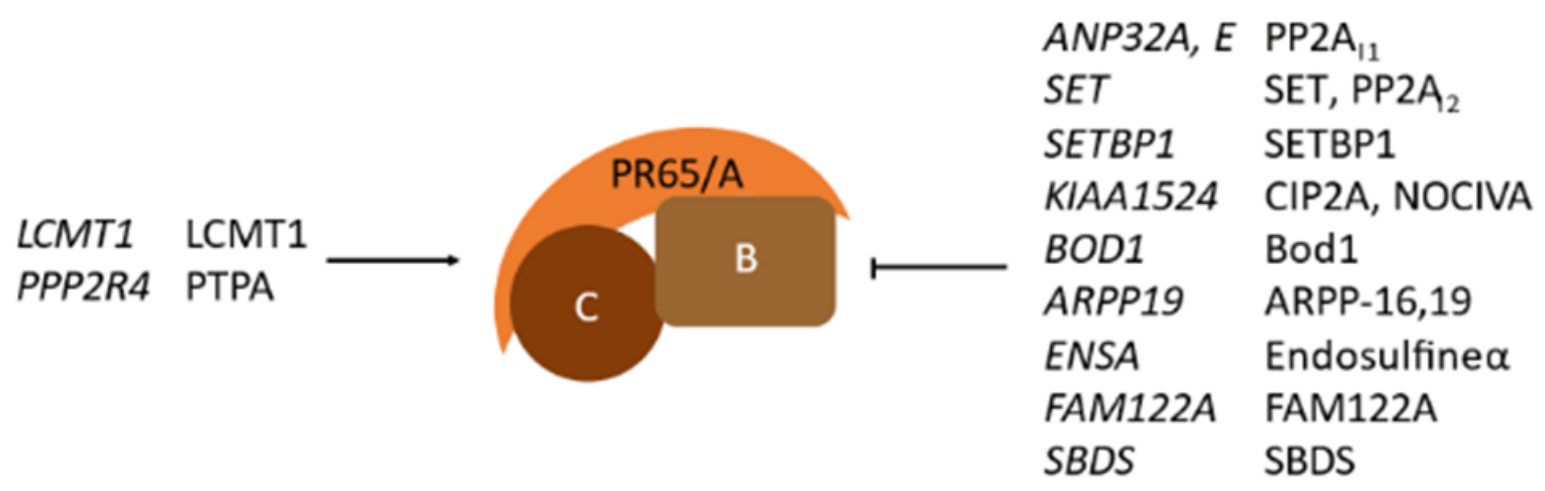

D
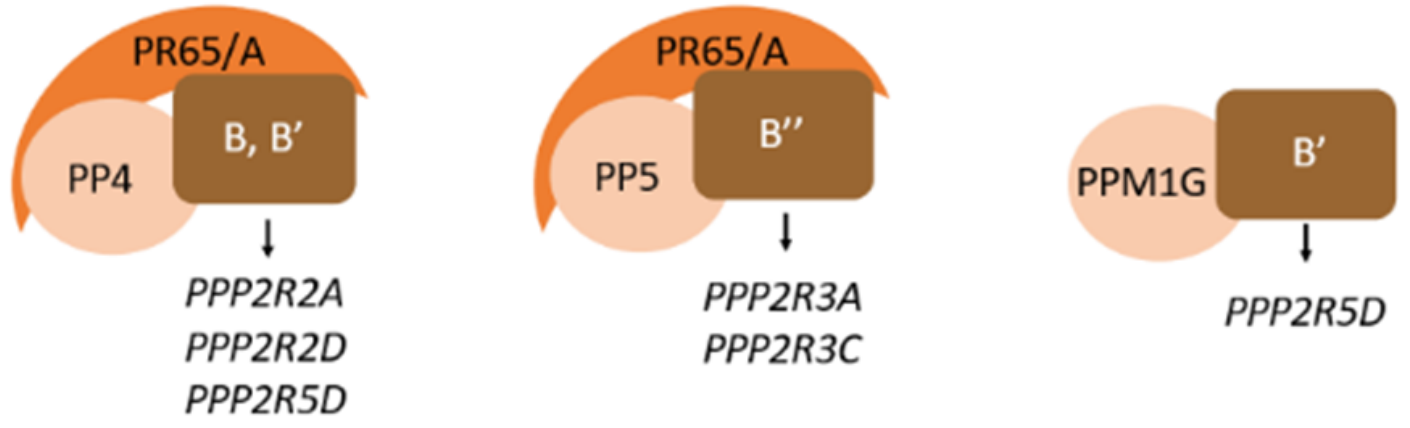


\section{A Mouse ENCODE mRNA expression}

\begin{tabular}{|c|c|c|c|c|c|c|c|c|c|c|c|c|c|c|c|c|c|c|}
\hline & $\mathrm{Ca}$ & $\mathrm{Cb}$ & R1a & R1b & $R 2 a$ & $R 2 b$ & $R 2 c$ & R2d & $R 3 a$ & $R 3 c$ & R5a & $R 5 b$ & $R 5 c$ & $R 5 d$ & R5e & Strn & Strn3 & Strn4 \\
\hline cerebellum & 94 & 29 & 134 & 5 & 7 & 13 & 65 & 7 & 3 & 6 & 10 & 51 & 13 & 32 & 9 & 7 & 18 & 20 \\
\hline frontal lobe & 83 & 30 & 129 & 3 & 10 & 23 & 88 & 6 & 3 & 6 & 21 & 30 & 17 & 22 & 8 & 6 & 14 & 36 \\
\hline cortex & 84 & 31 & 123 & 3 & 9 & 22 & 105 & 6 & 3 & 5 & 17 & 33 & 18 & 22 & 8 & 7 & 12 & 40 \\
\hline CNS E11.5 & 109 & 28 & 91 & 9 & 11 & 3 & 1 & 8 & 3 & 10 & 9 & 11 & 15 & 34 & 10 & 4 & 21 & 26 \\
\hline CNS E14 & 133 & 38 & 132 & 7 & 11 & 31 & 12 & 10 & 5 & 10 & 6 & 25 & 12 & 31 & 10 & 3 & 19 & 42 \\
\hline CNS E18 & 129 & 44 & 140 & 6 & 10 & 45 & 40 & 10 & 6 & 10 & 6 & 39 & 13 & 29 & 10 & 4 & 19 & 44 \\
\hline brain E14.5 & 113 & 38 & 147 & 7 & 9 & 30 & 16 & 11 & 5 & 9 & 5 & 31 & 11 & 30 & 10 & 3 & 17 & 51 \\
\hline
\end{tabular}

\section{B Human PROTEIN ATLAS expression}

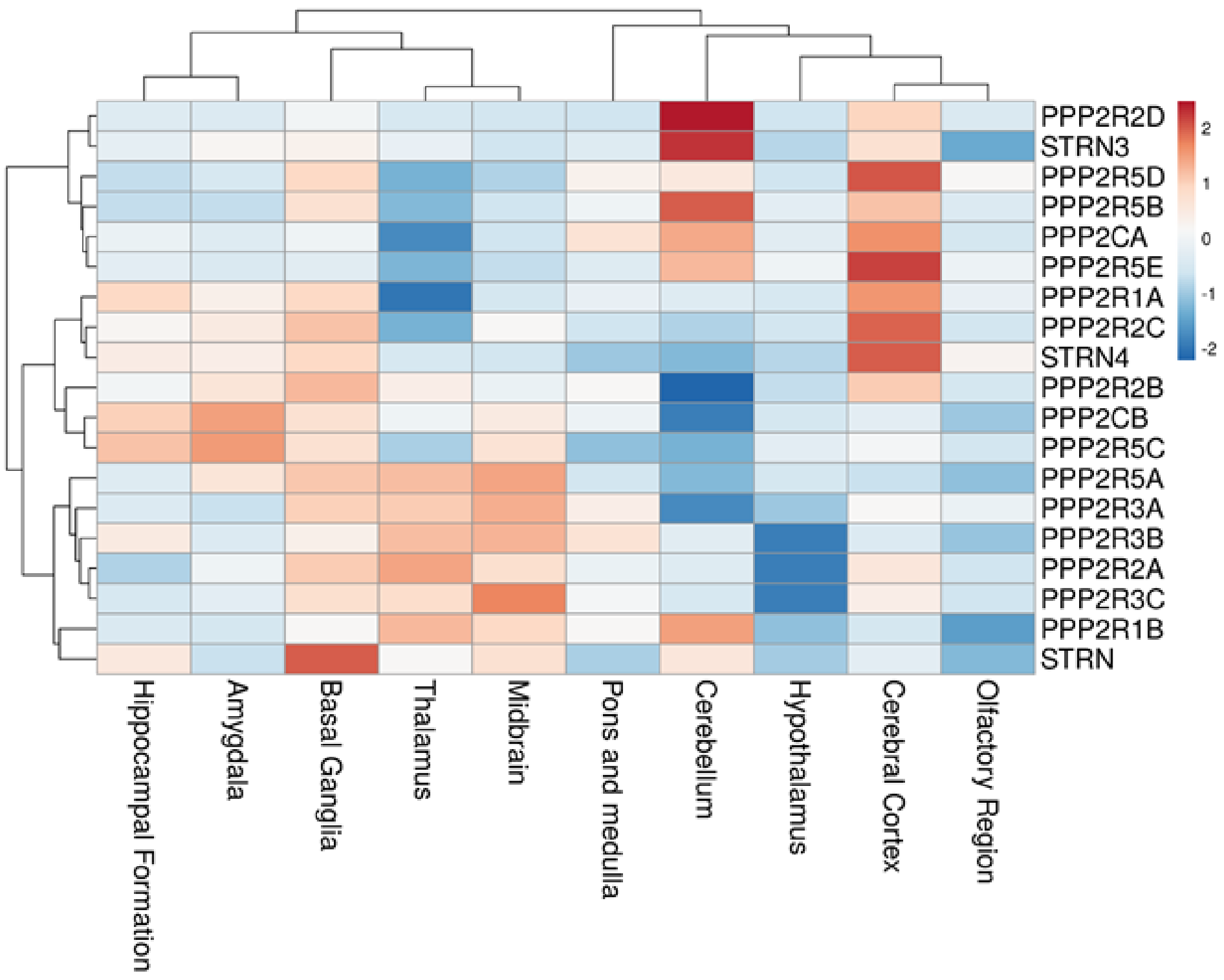


A

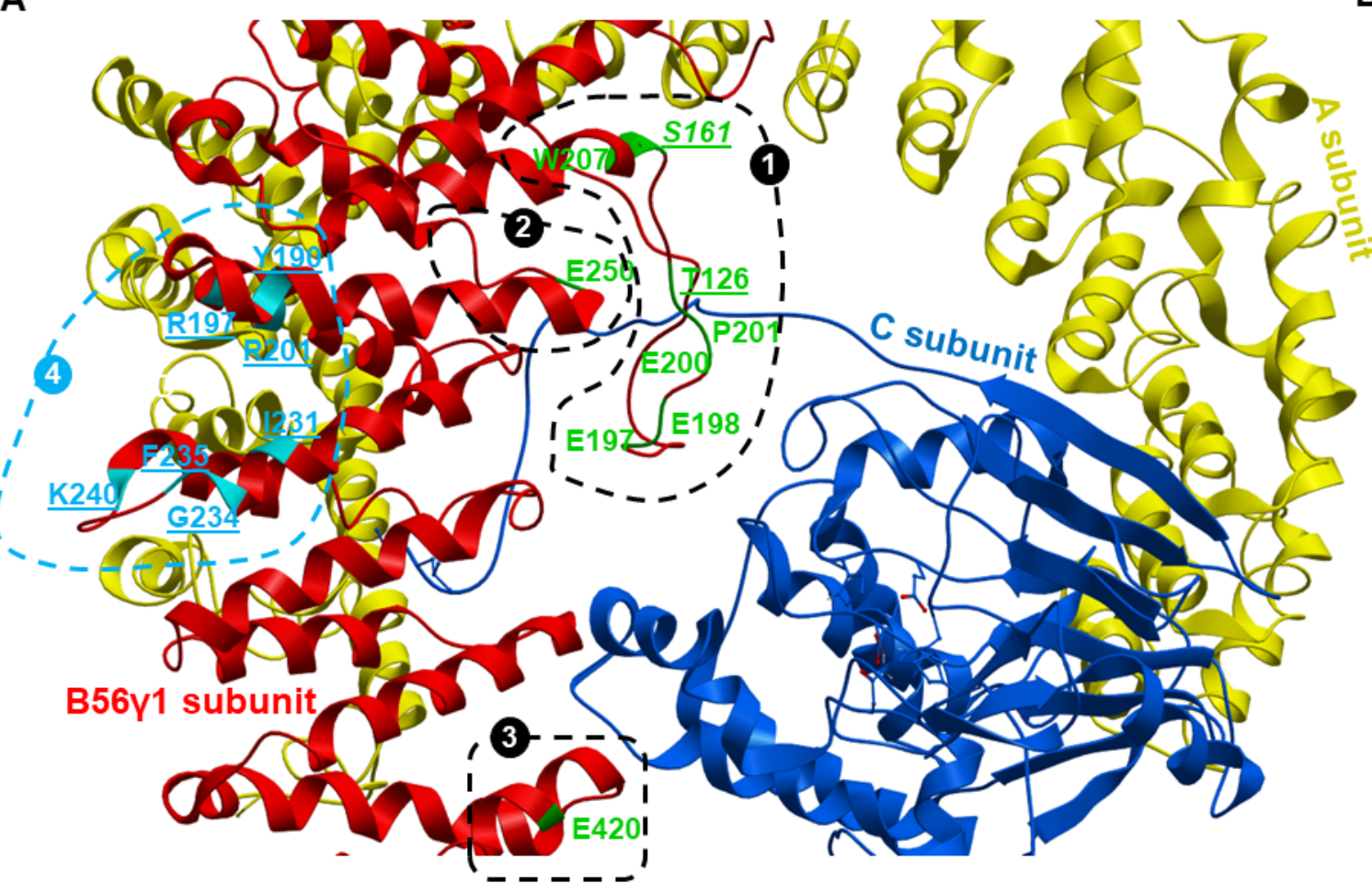

B

(1) Conserved acidic loop DFDPEEDEPTLEASWPHIQ EFDPEEDEPNLEPSWPHLQ EFDPEEDEPTLEAAWPHLQ

193-EFDPEEDEPTLEAAWPHLQ-211 EFDPEEDEPTLEASWPHLQ

(2) Conserved region, downstream of SLiM binding domain

ELFDSEDPRERD ELFDSEDPRERE

B56 $\alpha$ ELFDSEDPRERD B56 $\beta$ B56y 245-DIFDSEDPRERD-256 B56ठ ELFDSEDPRERD B56 $\varepsilon$

(3) Other conserved region

HFQVAERALYFWN B56 $\alpha$ HFQVAERALYFWN B56 $\beta$ HFQVAERALYYWN B56Y 415-HFQVAERALYYWN-427 B56ठ HFQVAERALYYWN $\quad$ B56 6

(4) SLiM-binding domain
B56 $\alpha$ B56 3 B56y B568 B56ع 
A

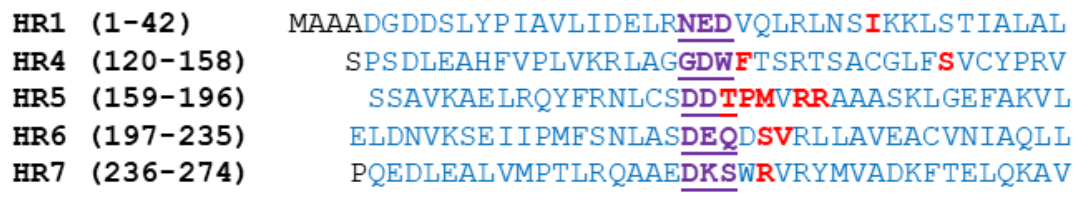

HR4 (120-158)

HR5 (159-196)

HR6 (197-235)

HR7 (236-274)

MAAADGDDSLYP IAVLIDELRNEDVQLRLNS IKKLS TIALAL SPSDLEAHFVPLVKRLAGGDWFTSRTSACGLESVCYPRV SSAVKAELRQYFRNLCSDDTPMVRRAAASKL GEFAKVI ELDNVKSE I IPMFSNLASDEQDSVRLIAVEACVNIAQLI PQEDLEALVMPTLRQAAEDKSWRVRYMVADKFTELQKAV

B

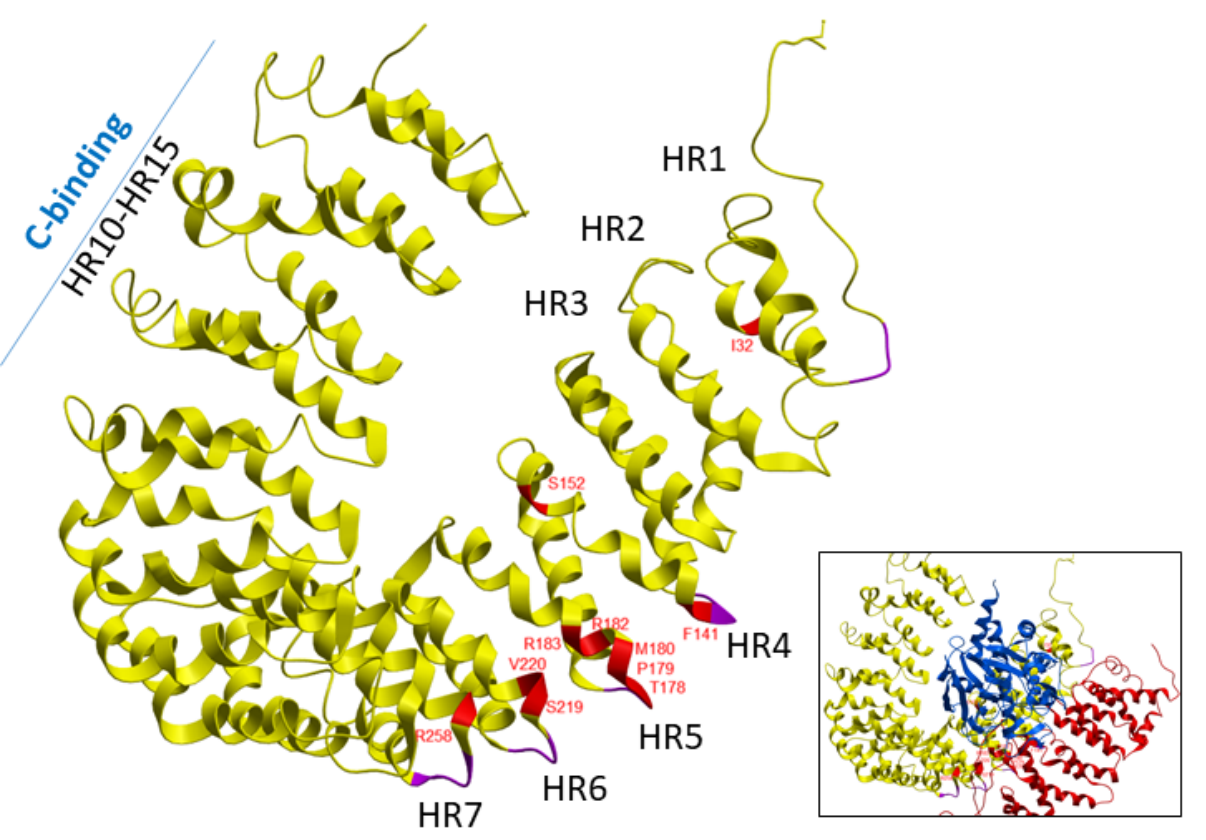

\section{B-type subunits} $\nearrow \downarrow \downarrow$
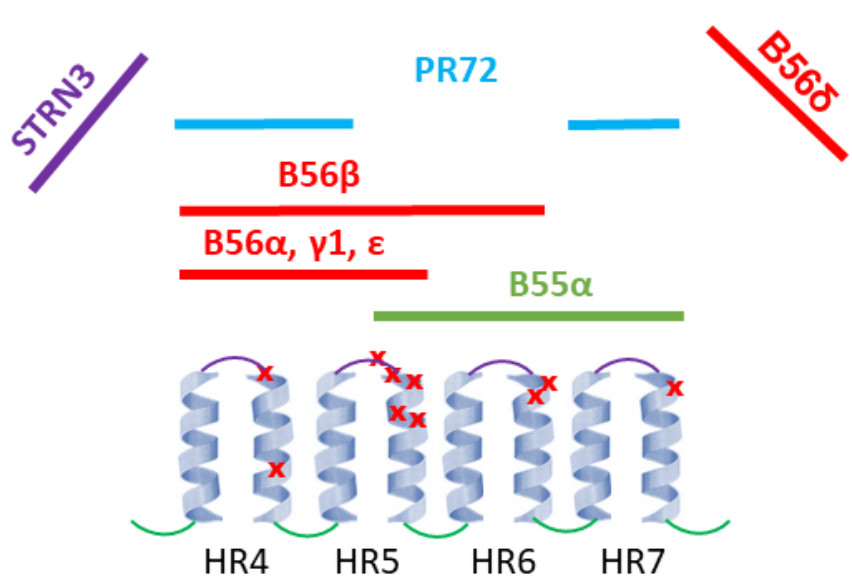


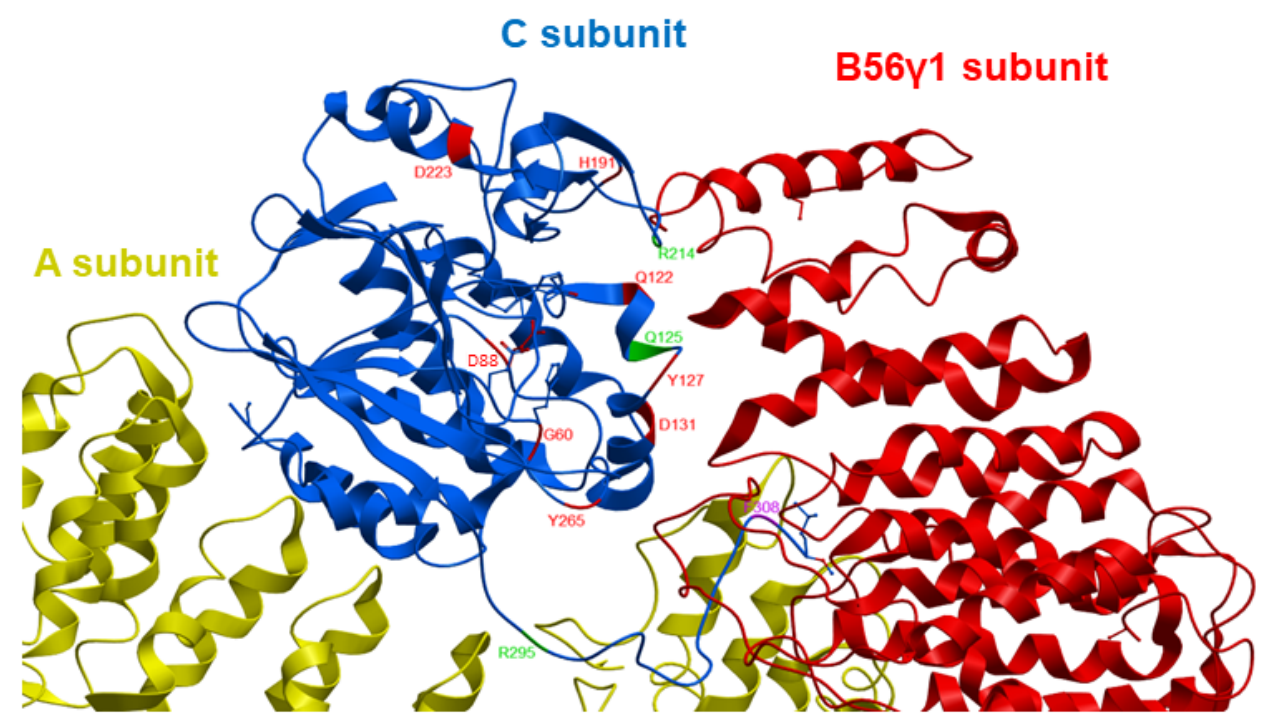

